\title{
Organizational Structure for the IT Department: Profit Center or Cost Center?
}

\author{
Joseph Vithayathil ${ }^{1}\left[\right.$ D $\cdot$ Vidyanand Choudhary $^{2}$
}

Accepted: 6 October 2021 / Published online: 18 January 2022

(c) The Author(s) 2022

\begin{abstract}
Why do some firms organize their IT departments as profit centers whereas other firms organize IT as a cost center? These commonly employed organizational structures are characterized by information asymmetry and decision rights afforded to the IT department. The complexity of IT and its ongoing rapid evolution lead to information asymmetry where the IT department has private information about technology and cost, and the consuming departments have private information about demand. Under the cost center organizational structure, the firm sets the quality and number of IT services offered by the IT department. Whereas under a profit center structure, the IT department makes decisions on quality, price and variety of IT services. We find that the quality of IT services under the cost center decreases with greater uncertainty in demand for IT services. We also find that the cost center structure can offer higher quality IT services than the profit center structure, and consumption of IT services can be higher under the profit center structure. The preferred organizational structure does not always provide greater variety of IT services than the alternate structure. The cost center is preferred when the marginal cost of IT services is sufficiently low, or the fixed cost of quality is sufficiently high.
\end{abstract}

Keywords Information technology $\cdot$ IT $\cdot$ IT governance $\cdot$ Cost center $\cdot$ Profit center $\cdot$ Chargeback

\section{Introduction}

We study the most common organizational structures for the IT department, the profit center and cost center organizational structures (Acemoglu et al., 2007; Allen, 1987; Gurbaxani \& Kemerer, 1988, 1989; Wang \& Barron, 1995). 52\% of the firms are organized as a profit center while the rest are cost centers (Techworld, 2004). The ideal organizational structure depends on various factors and sometimes firms need to change the IT department's organizational structure to obtain the optimal benefits from IT. For example, USAA (United Services Automobile Association), a large insurance company primarily serving US military families, had organized the IT department as a cost center under which their

Joseph Vithayathil

jvithay@siue.edu

Vidyanand Choudhary

veecee@uci.edu

1 Southern Illinois University Edwardsville, Edwardsville, IL, USA

2 University of California, Irvine, Irvine, CA, USA
IT spending was growing much faster than their revenues. Revenues grew 9\% while IT spending grew 19\% in 1999. That year, the CEO changed the organizational structure to a profit center. This strategy proved successful for USAA as costs were reduced and the quality of IT service improved (Overby, 2004). At USAA the significant organizational change to a profit center structure led to improvements in IT department customer service, quality of IT services and efficiency within the IT department. This example illustrates the significant impact that organizational structure can have on the benefit to the firm from IT.

The two governance structures are distinguished by differences in three characteristics: (i) the location of decision rights regarding quality, price and variety of IT services where under the cost center, the firm represented by the CEO makes the decision on quality and variety and offers IT service as a free corporate service. Under the profit center, the IT department represented by the CIO makes the decision on price, quality and variety; (ii) the criteria on which the decisions are made. Under the cost center structure decisions are made based on maximizing the benefits to the firm from IT services, whereas under the profit center structure the decisions are made on maximizing internal profits generated from IT services; (iii) the information 
state of the decision maker; and (iv) whether IT services are offered as a free corporate resource as in the cost center structure, or whether pricing of IT services is a decision variable as in the profit center structure.

The importance of IT governance and its relationship to business architecture, business operations such as outsourcing, and individual behavior has been highlighted by prior literature (Tonelli et al., 2017; Versteeg and Bouwman, Ali and Green, 2012; Wiedenhöft et al., 2020). Wu et al. (2015) state that in extant literature there exists a lack of clarity in our understanding of the mechanisms that affect IT governance which in turn affects organizational performance. Vejseli and Rossmann (2017) espouse similar concerns on the lack of understanding of IT governance and performance. Furthermore, recent literature provides additional evidence of the importance and relevance of understanding organizational structure as a mechanism for IT governance and its association with benefit or value to the organization (Aasi, 2018; Dawson et al., 2016; Larsson, Rusu and Aasi, 2015). Our research focuses on these stated concerns by modeling IT organizational structure as a governance mechanism that affects organizational benefits and therefore, organizational value.

Prior research has studied the profit center and cost center structures in the context of pricing. In contrast, this paper studies these two governance structures in the context of quality and variety of IT services. Quality of IT services has been discussed but has not been formally modeled in prior literature, except in the specific outsourcing case where IT services are provided through cloud computing (Choudhary $\&$ Vithayathil, 2013). The notion of variety of IT services, which is characterized by the number of distinct IT services offered by the IT department, has not been considered in prior research. This paper addresses this gap and analyzes quality and variety of IT services in addition to pricing. Furthermore, our analysis is applicable to each individual IT service such that each IT services can independently be governed by its preferred governance structure.

Our research objective is to understand the IT governance structure that is most beneficial to the firm and the conditions that determine the choice of organizational structure, and the effect of this structure on quality, consumption and variety of IT services. These questions are relevant because rapid technological change denoted today as Social, Mobile, Analytics and Cloud (SMAC) and the Internet-ofThings (IoT) are affecting organizational structure (Porter \& Heppelmann, 2015), and a suboptimal organizational structure could have significant impact on benefits because IT spending is the largest portion of non-residential spending amounting to almost 30\% in the US (Colecchia \& Schreyer, 2002). Practitioners and scholars highlight the importance of quality, consumption and variety of IT services. Prior research (Delone \& McLean, 2003) has shown that quality and variety of IT services affects net benefits to the firm. We show that organizational structure affects these important attributes of quality and variety of IT services.

Information asymmetry plays an important role in the choice of organizational structure as noted prior literature (Gurbaxani \& Kemerer, 1989; Wang \& Barron, 1995). For example, the IT department has significant information asymmetry with other business functions and departments whereas other departments such as Human resources (HR) and Accounting departments that are corporate functions do not have such information asymmetry. The reason is that IT requires specialized technical knowledge in software, networking, mobile communications, social media, analytics, cloud computing and cyber security (Florentine, 2017) among others. Such technically specialized information is the domain of CIOs and IT specialists, and because of this specialized technical nature, business managers typically have little understanding or expertise in IT. Even if the non-IT manager desired to gain IT understanding and expertise, this is difficult due to the rapidly changing nature of IT. Whereas, functions such as Accounting and HR are stable with minimal changes in technical knowledge.

Information asymmetry with regard to IT costs has been discussed earlier (Wang \& Barron, 1995). They note that the firm is poorly informed about the cost of IT but the IT department is fully informed of such costs. Similarly, Gurbaxani and Kemerer (1989) point out that the first best solution where the firm is fully informed and makes all IT related decisions is not feasible because of information asymmetry. Other literature highlights agency problems and information sharing issues associated with IT governance (Cumbie \& Sankar, 2012; Cumming et al., 2017).

We develop an analytical model to study the organizational structure that maximizes IT benefits to the firm and to understand the factors that affect this choice of structure. While there is significant prior literature in this area, there are only two analytical papers that have examined IT organizational structure. We show several novel results relating to IT organizational structure, quality of IT services and variety of IT services.

Consistent with prior literature (Acemoglu et al., 2007; Allen, 1987; Gurbaxani \& Kemerer, 1988, 1989; Wang \& Barron, 1995), we conceptualize the cost center organizational structure as one where non-IT executives such as CEO or CFO retain decision rights for price and quality of IT services. These non-IT executives do not have complete information about the cost and value of services, but can estimate them. In contrast, we define the profit center organizational structure as one where these decision rights reside with IT executives such as the CIO who is informed about cost and value of IT services.

We also analyze the impact of organizational structure on variety of IT services offered under each organizational 
structure. Variety of IT services refers to the number of distinct IT services that are available. While most firms may have a core set of IT services that support basic functions such as accounting and finance, other firms may offer greater variety of IT services by offering support for social media, hand-held mobile devices and the ability to generate realtime business analytics information.

\section{Literature}

Relevant literature can be grouped into four streams. The first stream of prior literature is qualitative in nature. Several qualitative papers in prior literature have provided arguments in favor of the cost center or the profit center or discussed the advantages and disadvantages of each organizational structure for the IT department (Allen, 1987; Gurbaxani \& Kemerer, 1988; Gurbaxani \& Kemerer, 1989; Jensen \& Meckling, 1998; Ross et al., 1999). Within this stream of literature, Gurbaxani and Kemerer $(1988,1989)$ use economics-based arguments to discuss the consequences of organizing the IT department as a cost center or as a profit center. As noted in the Introduction section, they point out that the first best solution where the firm is fully informed and makes all IT-related decisions is not feasible because of information asymmetry. They argue that the end user is knowledgeable about the value of IT services consumed while the IT department is knowledgeable about the cost of such services. Further, they claim that top management is neither fully informed about the demand for IT services nor about the cost of these services. Gurbaxani and Kemerer (1988) argue that the profit center encourages efficiency but creates a local monopolist that may not always keep the firm's benefit as a priority whereas a cost center structure encourages excessive consumption while maximizing firm benefits. They also note that the profit center structure will charge high prices for IT services, which will constrain consumption. Prior literature (Jensen \& Meckling, 1998) also discusses the impact of organizational structure on any generalized supplier of internal services within a firm. The argument made is that when internal services are free, there is no incentive for the functional unit using such services to regulate their consumption levels for the overall benefit of firm. Others (Allen, 1987) argue in favor of a profit center approach to ensure prudent consumption of IT services. Additionally, the importance of organizational structure and its role as a mechanism for resolving information asymmetry is widely discussed in prior literature (Eccles and White, 1988; Stinchcombe, 1990; Hann \& Weber, 1996; Jensen \& Meckling, 1998; Weill and Ross, 2004). More recent IT governance literature emphasizes the application of agency theory to IT governance and describes the role of information asymmetry in IT governance (Dawson et al., 2016; Luo et al., 2016; Sharma \& Gupta, 2019; Stablein, 2018).

The second stream of literature employs analytical models to understand the cost center and the profit center for the IT department (Choudhary \& Vithayathil, 2013; Wang \& Barron, 1995). Wang and Barron (1995) developed an analytical model that compares the value to the firm from the IT department organized as a profit center or as a cost center. They develop a queuing model where users submit computing jobs to the IT department and users incur a delay cost based on the waiting time. Such models are best suited for situations where computing infrastructure is expensive such as with mainframe computing. Wang and Barron (1995) also incorporate information asymmetry in their model where the IT manager has private information on IT costs and maximizes her private benefits by over-representing IT costs to the firm. They find that the profit center is never optimal because the information rent under the profit center is never less than the loss of value from information asymmetry under the cost center. This result is surprising given the observable prevalence of both organizational structures in practice. Our paper is different from Wang and Barron in several aspects. Our model includes quality of IT services (Magal, 2015) and variety of IT services, which are not analyzed in Wang and Barron. Additionally, our model assumes information asymmetry with regard to demand for IT services, whereas they assume the firm and the IT manager are perfectly informed about demand for IT services. Our results show that either organizational structure can be beneficial to the firm depending on the conditions, whereas Wang and Barron find that the cost center is always the preferred organizational structure for the IT department. The second paper by Choudhary and Vithayathil (2013) which employs an analytical model is solely focused on a special case of outsourcing with cloud computing. They find that the intensity of competition faced by the cloud vendor affects the choice of organizational structure.

The third stream of literature that analyzes organizational structure for the IT department is empirical (Acemoglu et al., 2007; Bergeron, 1986; Ross et al., 1999). This literature includes discussions with several firms to study the effect of pricing internal IT services (Ross et al., 1999) and concludes that such pricing reduces consumption. They support earlier conclusions arrived at by using survey data (Bergeron, 1986). Others (Acemoglu et al., 2007) provide an empirical study of the effect of organizing the IT department as a cost center or a profit center on the diffusion of new technologies. Earlier literature provide frameworks for such organizational structure analysis (Yadav, 1985).

A fourth stream of literature analyzes pricing of IT services in the context of delay costs (Dewan, 1996; Dewan \& Mendelson, 1990; Joe-Wong \& Sen, 2018; Mendelson, 1985; Pick \& Whinston, 1989). However, this stream does 
Table 1 Conceptual summary of governance structure and prior literature

\begin{tabular}{|c|c|c|c|c|}
\hline & Location of decision rights & $\begin{array}{l}\text { Information state of decision } \\
\text { maker }\end{array}$ & Decision criteria & Decision variables \\
\hline Cost center & Firm (represented by CEO) & Cost and demand uncertainty & $\begin{array}{l}\text { Maximize firm benefit from IT } \\
\text { services }\end{array}$ & $\begin{array}{l}\text { Quality and variety. } \\
\text { Price nominally set } \\
\text { to zero }\end{array}$ \\
\hline \multirow[t]{4}{*}{ Profit center } & $\begin{array}{l}\text { IT department (represented by } \\
\text { CIO) }\end{array}$ & $\begin{array}{l}\text { Fully informed about cost and } \\
\text { demand }\end{array}$ & Maximize IT department profit & Price, quality and variety \\
\hline & Qualitative literature & $\begin{array}{l}\text { Allen (1987) } \\
\text { Eccles and White (1988) } \\
\text { Gurbaxani and Kemerer (1988 } \\
\text { Stinchcombe (1990) } \\
\text { Hann and Weber (1996) } \\
\text { Jensen and Meckling (1998) } \\
\text { Ross et al. (1999) } \\
\text { Weill and Ross (2004) } \\
\text { Peterson (2004) }\end{array}$ & 89) & \\
\hline & Modeling literature & \multicolumn{3}{|c|}{$\begin{array}{l}\text { Wang and Barron (1995) } \\
\text { Choudhary and Vithayathil (2013) }\end{array}$} \\
\hline & Empirical literature & $\begin{array}{l}\text { Bergeron (1986) } \\
\text { Ross et al. (1999) } \\
\text { Acemoglu et al. (2007) }\end{array}$ & & \\
\hline
\end{tabular}

not address the choice of organizational structure for the IT department and the consequences that result from the choice of structure. In this stream, scholars (Mendelson, 1985) have found that the addition of user delay cost in a queuing model leads to the optimality of excess capacity, and others have extended this work (Dewan, 1996; Dewan \& Mendelson, 1990). We also note that economic models such as in Tirole (1988) do not consider information asymmetry.

We build on this literature by incorporating new factors such as quality of IT services (Magal, 2015), variety of IT services and demand information asymmetry that have not been modeled previously. Quality of IT services is important to the firm because intuition suggests that low quality IT services can lead to significant problems. Following prior literature (Gurbaxani \& Kemerer, 1989; Wang \& Barron, 1995), we assume that the IT department has private information about the cost of IT services. The business units that consume IT services are knowledgeable about the value or benefit they obtain from IT services. The IT department can learn the demand for its services through regular interactions with the business units. For example, when USAA switched to a profit center structure they misestimated demand for the first year but learned it for subsequent years (Overby, 2004).

We compare analytical models of the cost and profit center and find the cost center structure can offer higher quality IT services than the profit center structure, which is surprising because prior literature (Allen, 1987) argues that the IT department organized as a profit center will offer higher quality of IT services. Hence, it is possible that firms may be adopting a structure that does not deliver the greatest quality of IT services and prior literature (Delone \& McLean, 2003) has shown quality to be an important factor in generating benefits. We also find that the quality of IT services set by the firm under the cost center structure is decreasing in the level of uncertainty about the amount of IT service usage by the internal IT-consuming business functions. Such uncertainty arises from information asymmetry between the management of the firm and the IT department. Another interesting result is that the preferred organizational structure does not always provide the greatest variety of services. The cost center can offer greater variety of IT services compared to the profit center even when the profit center is the preferred organizational structure.

Table 1 provides a conceptual summary of governance structure and prior literature.

\section{Model}

We develop a stylized model to compare the benefits of organizing the IT department as a cost center or as a profit center. A conceptual model is described in this section 
followed by an analytical model that builds on the conceptual view. The structure of the IT department impacts the quality, quantity and variety of IT services, and the effect on benefits the firm derives from IT services. We focus only on those services that the firm offers through its internal IT department, therefore functional units that consume IT services must obtain these services from the IT department. The amount and nature of IT services demanded by the functional units depends on a variety of factors such as external market conditions, the nature of the product, the degree of competition faced by the firm etc. Our model abstracts these factors, capturing them in an aggregate demand function.

\subsection{Conceptual Model of IT Organizational Structure}

Our model considers three players, namely: (i) the IT department, which provides IT services; (ii) the functional unit which consumes IT services (for ease of exposition and without loss of generality, the consuming functional units are abstracted into a single monolithic unit) and; (iii) the firm represented by non-IT executives such as the CEO.

There is ample literature that establishes the role of organizational structure and decision rights as a seminal topic in IT governance. Stinchcombe (1990) notes that organizational structure with the associated decision-making rights is used by firms to resolve information asymmetries. In consonance with this view, Banker et al. (2011) shows that reporting structure is associated with firm performance. Peterson (2004) finds that IT governance itself is the attribution of decision rights to appropriate stakeholders and in similar vein, Weill and Ross (2004) demonstrate the role of decision rights in determining the efficacy of generating IT benefits to the firm. Earlier, Eccles and White (1988) note that price and authority are dual decision rights that determine resource allocation. Extending these concepts, Jensen and Meckling (1998) delineate general knowledge and specific knowledge and note that firms deal with such information asymmetry through decision rights embedded in organizational structure such as the cost center and profit center. Hann and Weber (1996) use such concepts and apply them to information systems and note that top management is not well informed about information systems compared to the IT manager and this asymmetry of information is dealt with by allocating decision rights. We build on this prior literature to develop our model of the cost center and profit center that make decisions on price and quality. Hence, the firm can select one of two IT organizational structures: (a) a cost center or; (b) a profit center.

Under the cost center organizational structure, (i) The firm determines the quality of IT services to maximize total benefit to the firm; (ii) IT services are provided at no charge to the functional units; (iii) The functional unit determines the amount of IT services to consume based on its demand function; (iv) The firm incurs the cost for providing such services; and (v) The benefit to the firm from IT is determined by the surplus generated by the functional unit from the consumption of IT services net of IT costs. It is important to note that optimal quality determined by the firm under the cost center organizational structure is not the same as the social planner's choice of quality for several reasons. First, note that under the cost center model, the firm sets a price for IT services that is normalized to zero so that IT services are provided as a free corporate resource. This is consistent with Gurbaxani and Kemerer $(1988,1999)$ where they discuss the benefit from offering IT services as a free corporate resource. Hence, price is not a decision variable under the cost center model. Second, under the cost center model, there is information asymmetry with respect to IT cost and demand for IT services so that the firm/CEO is not perfectly informed of the cost of IT quality, and the value of IT quality to the functional unit. The decision rights under the cost center model rest with the CEO or a non-IT manager such as the CFO.

Under the profit center organizational structure, (i) the IT department determines the price and quality of its services to maximize its profit; (ii) The functional unit determines the amount of IT services to consume based on its demand function and the price; (iii) The IT department incurs the cost for providing IT services; and (iv) The benefit to the firm from IT is the sum of the surplus generated by the functional unit from consuming IT services and the profits of the IT department. Finally, we analyze an extension that compares the variety (number) of IT services offered under a cost center structure to that offered under a profit center structure.

As discussed in the Introduction section, our model incorporates information asymmetry with respect to cost and demand for IT services. We now clarify each player's information set. The functional units are informed about the price and quality of IT services available from the IT department and can compute their surplus from using such IT services and are therefore informed about the demand function but not the cost of delivering the IT services. The IT department is informed about the cost of delivering IT services and learns the demand function in the course of providing such IT services. The firm has imperfect information about both the cost of IT services as well as demand for IT services.

A brief discussion of the marginal costs of IT services is warranted to clarify the distinction between information goods and IT services. While packaged software and digital goods are generally regarded to have zero marginal cost, corporate IT services do not fall in this category. Examples of IT services are (a) WAN/LAN services which have cost per megabit; (b) Smart phones which have subscription based monthly charges; (c) Storage and Backup with cost per GB, (d) ERP / EDA Software licenses that typically have a fixed 
price component and a variable component based on the number of users and; (e) technical support which requires increasing labor costs as a function of the demand. We capture these characteristics by assuming a marginal cost associated with such services. Oi (1962) notes that labor has a variable component and Allen (1987) provides evidence that a significant portion of IT cost is marginal cost. Therefore we treat a portion of IT labor such as the CIO and other management personnel as fixed costs, while other components such as technical staff are treated as marginal cost.

Quality of IT services includes the timeliness of the initial response and the speed of resolution of service requests; the availability of customized reports; accuracy of reports; increased software applications functionality and features; ease of use or intuitive user interface; and other metrics such as low latency networking, storage, and computing. Increasing the quality along such lines is costly and this cost is related to the quantity of services consumed. For example, as more users are added to subscription based services such as smart phone services, the cost of increasing the quality of technical support increases because more labor is required for such quality improvement. Thus, the marginal cost of IT services has two components, a base level of marginal cost for providing the base service, and the rate of increase of marginal cost with increasing quality. Improving the quality of IT services will also incur a fixed cost. For example, IT quality metrics such as high levels of redundancy in storage, computing, or networking will require additional capital for multiple backup systems or failover systems.

\subsection{Linear Demand Model}

We develop a stylized model that simplifies many issues to focus on key economic parameters for reasons of tractability and exposition. The model considers three players: (1) the IT department; (2) the functional unit that is a consumer of IT services and; (3) the firm represented by the CEO. The first player, the IT department provides $x$ quantity of services at a quality level $q$ to the functional unit. Such services have a cost consisting of (i) a marginal cost $(c+q)$ which depends on the base marginal cost $c$ and the quality level $q$ for each unit of service, (ii) a convex fixed cost of quality denoted by $g(q)$ and; (iii) a general IT fixed cost $F$. The second player, the functional unit consumes IT services to maximize the value of its business. The functional unit may face external market conditions that affects its demand for IT services. The functional unit's demand function for IT services is $D(p, q)$, whereprepresents the price charged by the IT department for IT services, and the parameters of this function reflect external market conditions as well as the functional unit's production function. We assume that $D(p, q)$ is exogenously specified. The firm is interested in generating the greatest benefits from the use of IT services under information asymmetry.

Information asymmetry under the cost center structure is captured by the introduction of random variables for cost information asymmetry and demand information asymmetry. These random variables introduce noise into the cost and demand functions and we model the firm's imperfect information set using such noisy information. Under the profit center, the IT department determines price and quality, and it has perfect information about the cost of information technology and imperfect information about demand. Whereas under the cost center, the firm determines price and quality based on imperfect information about demand and cost. The total cost of IT services under the two organizational structures are expressed as follows:

$\tilde{C}_{I T}=x(c+q)+\tilde{g}(q) \quad$ cost center : cost under information asymmetry

$C_{I T}=x(c+q)+g(q)$ profit center : cost under full information

The fixed cost of quality $g(q)$ is observable by the IT department, whereas the firm and the IT department observe $\tilde{g}(q)$. As shown in Eq. 1, $\tilde{C}_{I T}$ is a function $\tilde{g}(q)$. The demand function under the two organizational structures is expressed as:

$x=\tilde{D}(p, q)$ demand function under information asymmetry

Equations 1 and 2 capture the concept that the firm is imperfectly informed about IT cost from $\tilde{C}_{I T}$ and that the firm and the IT department is imperfectly informed about IT demand from $\tilde{D}(p, q)$.

The firm's optimization problem under the cost center organizational structure is to determine quality ${ }^{1}$ to maximize:Max $\left\{E\left[S_{f}\right]\right\}$, where $S_{f}=\int_{0}^{x}\left(\tilde{D}^{-1}(x, q)\right) d x-\tilde{C}_{I T}$. The inverse demand function $\tilde{D}^{-1}(x, q)$, is the willingness-to-pay (WTP) for IT services by the consuming functional unit. The IT department's optimization problem under the profit center organizational structure is to determine price and quality to maximize IT profits:Max $\left\{S_{I T}\right\}$, where $S_{I T}=\tilde{D}(p, q) \cdot p-C_{I T}$.

The third player is the firm, which is an aggregation of the functional unit and the IT department. The firm chooses the organizational structure that provides greater benefit to the firm from IT services. The benefit to the firm from the cost center is $S_{f}$, and the benefit to the firm from the profit center is $S_{I T}+S_{U}$, where $S_{U}=\int_{0}^{x}\left(\tilde{D}^{-1}(x, q)\right) d x-\left(\tilde{D}^{-1}(x, q) D(p, q)\right)$ is the surplus

\footnotetext{
$\overline{{ }^{1} \text { Firms may }}$ set quality through external benchmarking or by estimating their business needs. See for example Gordon (1994).
} 
generated by the functional unit from the consumption of IT services.

\subsection{Assumptions}

A1. Regularity Conditions Standard mathematical regularity conditions are assumed. The demand and profit functions are continuous, and the payoff functions are twice differentiable. Demand is increasing in quality and decreasing in price: $\frac{\partial D(\cdot)}{\partial q}=D_{q}(p, q)>0, \frac{\partial D(\cdot)}{\partial p}=D_{p}(p, q)<0$. The cost of quality is increasing with quality: $\frac{\partial g(q)}{\partial q}=g_{q}(q)>0, \quad \frac{\partial^{2} g(q)}{\partial q^{2}}=g_{q q}(q)>0$. Therefore, the cost of quality function is convex. IT profit and benefit to the firm are concave functions. The inverse demand function exists and $\frac{\partial D^{-1}(\cdot)}{\partial q}=D_{q}^{-1}(x, q)>0$.

A2. Consumption Limits For each quality level, there is a threshold of maximum consumption denoted by $D(p=0, q)$ when price is zero. Similarly, at a sufficiently high price denoted by $D^{-1}(x=0, q)$ there will be no consumption of IT services.

The literature in economic modeling commonly employ linear demand functional forms to derive interesting properties of complex systems (Alperovich \& Weksler, 1996; Varian, 1992). The linear demand model has been widely used in prior literature as in Dixit (1979), Banker et al. (1998), Gal-Or (1985), Gal-Or and Ghose (2005), Vives (1984), and Singh and Vives (1984). It captures the intuitive notion of demand increasing with quality and decreasing with price. Consistent with prior literature we employ a linear functional form for the internal demand for IT services to determine equilibrium solutions and develop additional results. Our linear demand model has the well-used characteristics of increasing demand with quality and decreasing demand with price. Information asymmetry is captured by the random variable $\tilde{\gamma}$ for demand information asymmetry and cost information asymmetry. For tractability and ease of exposition, $\tilde{\gamma}$ is characterized by the Uniform distributions $\tilde{\gamma} \sim U(-\varepsilon, \varepsilon)$. Note that under the profit center structure the IT department has perfect information about IT cost such that $\tilde{\gamma}=0$. However, under information asymmetry the firm has imperfect information about its demand and cost function. Such imperfection is captured using the random variable $\tilde{\gamma}$, which introduce noise into the firm's information on demand and cost and the IT department's information on demand. The following demand function is employed in order to analyze the impact of the organizational structure on (i) quality; (ii) consumption or quantity; and (iii) variety of IT services.

$x=k-\alpha p+(\beta+\tilde{\gamma}) q$

The variables $(x, q, p)$ used in the equation above have been defined previously in this section. Under the cost center, the firm does not have full information about the demand parameter $\beta$ but knows the distribution of the random variable that represents demand, $(\beta+\tilde{\gamma})$. The firm incurs a marginal cost $(c+q(1+\tilde{\gamma}))$, where $(c)$ is the marginal cost independent of quality and $q(1+\tilde{\gamma})$ is the marginal cost of quality with embedded noise in the cost information. The firm also incurs a convex fixed cost of quality denoted by $\tilde{g}(q)=\left((a+\tilde{\gamma}) \cdot q^{2}\right)$ where the random variable $(a+\tilde{\gamma})$ is a scaling parameter for the fixed cost of quality. Additionally, there is a fixed cost of IT denoted as $(F)$ that is independent of quality and consumption. Therefore, the cost of IT services is expressed as:

$\tilde{C}_{I T}=x(c+q(1+\tilde{\gamma}))+(a+\tilde{\gamma}) q^{2}+F$

For simplicity and ease of exposition, the minimum acceptable quality of IT services is normalized to zero. The intercept of the demand function is denoted by the parameter $k$. The inverse demand function $\tilde{D}^{-1}(x, q)$ specifies the price $p$ for IT services, where $p=(k+(\beta+\tilde{\gamma}) q-x) / \alpha$ provides the willingness-to-pay (WTP) for such IT services by the functional unit which is the internal consumer of IT services. We integrate WTP to determine the surplus of the functional unit:

$S_{U}=\int_{0}^{x}\left(\frac{k+(\beta+\tilde{\gamma}) q-x}{\alpha}\right) d x-(p \cdot x)$

Under the profit center governance structure, the IT department is imperfectly informed about demand and has a noisy estimate of the demand parameter $(\beta+\tilde{\gamma})$, but understands the true cost and is informed about the cost parameter (a). Variables and parameters employed in this section are summarized in Table 2 in Appendix 1.

The two IT organizational models of a cost center and a profit center are analyzed separately in the following sections and the results are compared to develop the propositions. The sections that follow perform a separate analysis of each organization structure. A theoretical benchmark first-best solution is considered prior to analyzing the two governance models.

\section{First Best Solution}

For completeness, we analyze a theoretical first best solution for the firm where it is perfectly informed about demand and cost. The first best solution occurs at the quality and price levels that maximizes firm benefit. This occurs when the firm prices its services at marginal cost and maximizes quality $\left.\operatorname{Max}_{q}\left\{S_{I T}\right\}\right|_{p=(c+q), \tilde{\gamma}=0}$. 


\subsection{Lemma 1: First Best Benchmark Solution under Perfect Information}

When perfectly informed about IT cost and demand, the firm determines the First Best optimal price and quality to be: $p^{* F B}=\frac{2 a c \alpha+(\beta-\alpha)(k-c \beta)}{2 a \alpha-(\beta-\alpha)^{2}}, q^{* F B}=\frac{(\beta-\alpha)(k-c \alpha)}{2 a \alpha-(\beta-\alpha)^{2}}$, the benefit to the firm is: $S_{f}^{* F B}=\frac{a(k-c \alpha)^{2}}{2 a \alpha-(\beta-\alpha)^{2}}-F$, and the quantity of IT services consumed is: $x^{* F B}=\frac{2 a \alpha(k-c \alpha)}{2 a \alpha-(\beta-\alpha)^{2}}$.

Lemma 1 reports the First Best level of consumption, functional unit surplus, and benefit to the firm when the firm determines the optimal price and quality. The firm sets price equal to marginal cost, which eliminates deadweight loss and generates maximal firm benefit. The proof is in Appendix 1.

\section{IT Department Organized as a Cost Center}

Under a cost center governance structure, the firm determines quality of IT services and does not charge for these IT services. For tractability and convenience, the price for IT services is nominally set to zero. The essence of the analysis and results will not change if the price is non-zero. The key point to note is that price is not a decision variable arrived at by a cost or benefit optimization process. The firm is not perfectly informed about the IT demand function and the IT cost function and the expected benefit to the firm from IT is the expected surplus generated by the functional unit less the cost of IT, and is expressed as follows: the firm determines the optimal cost center quality level to be $q^{* C C}$. Firm benefit and consumption are based on the realization of actual demand because the consuming unit is informed of its own demand, and now knows quality of IT services. Because the price for IT services is not a decision variable and normalized to zero under this organizational structure, the functional unit will consume the maximum quantity under its demand function and therefore, will suffer no deadweight loss. However this leads to suboptimal consumption where users consume IT services even when value from the services is less than what could be generated if the firm were perfectly informed about demand and cost. Such suboptimal consumption which prior literature refers to as inefficient, leads to greater reduction in benefit to the firm when the marginal cost of the service is high. The marginal cost is higher when the quality of IT services is higher. Thus, improving quality of IT services under a cost center structure can lead to lower benefit to the firm. Therefore, the firm may prefer to offer lower quality under a cost center structure. From the expression for the optimal quantity of IT services consumed we can observe that when the firm's estimate of demand and cost is more noisy, then the level of consumption of IT services increases. This is an interesting result and we provide an explanation for this finding following Proposition 1 . The proof is in Appendix 1.

$E\left[S_{f}^{C C}\right]=E\left[\left(\int_{0}^{(k+(\beta+\tilde{\gamma}) q)} \frac{(k+(\beta+\tilde{\gamma}) q-x)}{\alpha} d x\right)-\left((k+(\beta+\tilde{\gamma}) q)(c+q(1+\tilde{\gamma}))+(a+\tilde{\gamma}) q^{2}+F\right)\right]$.

\subsection{Lemma 2: Interior Solution for IT Department as a Cost Center}

Under the cost center organizational structure, the firm determines the optimal quality to be: $q^{* C C}=\frac{3(k(\beta-\alpha)-c \alpha \beta)}{6 \alpha(a+\beta)-3 \beta^{2}+(2 \alpha-1) \varepsilon^{2}}$, the benefit to the firm is:

$S_{f}^{* C C}=\frac{\left(\begin{array}{l}6 \alpha(a+\beta)-3 \beta^{2}+(2 \alpha-1) \varepsilon^{2} \\ 36 a^{2} c k \alpha^{2}+9 a\left(2 c k \alpha(3 \alpha-2 \beta) \beta-c^{2} \alpha^{2} \beta^{2}+k^{2}\left(\beta^{2}-\alpha^{2}\right)\right)+ \\ 12 a c k \alpha(2 \alpha-1) \varepsilon^{2}+\left(3(\beta-\alpha)(k-c \beta)+c(2 \alpha-1) \varepsilon^{2}\right) \\ \left(3 \alpha \beta(k-c \beta)+k(2 \alpha-1) \varepsilon^{2}\right)\end{array}\right)}{2 \alpha\left(6 \alpha(a+\beta)-3 \beta^{2}+(2 \alpha-1) \varepsilon^{2}\right)^{2}}-F$, and the quantity of IT services consumed is: $x^{* C C}=k+\frac{3 \beta(k(\beta-\alpha)-c \alpha \beta)}{6 \alpha(a+\beta)-3 \beta^{2}+(2 \alpha-1) \varepsilon^{2}}$.

Lemma 2 reports the level of consumption, functional unit surplus, and benefit to the firm when

\subsection{Proposition 1: Effect of Information Asymmetry on Quality and Consumption of IT Services}

Under the cost center organizational structure, the optimal quality of IT services and consumption of IT services are decreasing in the firm's uncertainty. $\frac{\partial q^{* C C}}{\partial \varepsilon}=-\frac{6(2 \alpha-1)(k(\beta-\alpha)-c \alpha \beta) \varepsilon}{\left(6 \alpha(\alpha+\beta)-3 \beta^{2}+(2 \alpha-1) \varepsilon^{2}\right)^{2}}<0 \quad, \quad$ a $\mathrm{n} \mathrm{d}$ $\frac{\partial x^{* C C}}{\partial \varepsilon}=-\frac{6(2 \alpha-1) \beta(k(\beta-\alpha)-c \alpha \beta) \varepsilon}{\left(6 \alpha(a+\beta)-3 \beta^{2}+(2 \alpha-1) \varepsilon^{2}\right)^{2}}<0$.

The results reported in Proposition 1 are interesting because the firm reduces IT service quality under increasing uncertainty. The intuition behind this result comes from understanding the manner in which the benefits to the firm are generated from the use of IT services. Higher uncertainty translates to an increased range of demand possibilities and marginal cost 
possibilities. Increasing quality always costs more and if demand is insufficient firm benefit is adversely affected. In contrast, if quality is lowered cost is also lowered and firm benefit is less affected by lower stochastic draws in demand. Increasing uncertainty implies that demand has a wider range of stochastic draws. While demand is linear with respect to quality, the cost of quality is convex. Hence, the intuition is that expanding the range of uncertainty in demand forces the firm to lower quality because the severe cost penalty imposed when lower occurrences of demand are paired with higher quality.

An example could be online order placement at an e-commerce retailer when introducing a product with high uncertainty in demand and high cost of service quality. The number of customers placing orders has a wide range on uncertainty because of the untried and untested nature of the product introductions. Our finding suggests that the e-commerce retailer should resource for lower IT quality by provisioning fewer servers, storage and related hardware under greater uncertainty. As uncertainty is reduced, the e-commerce merchant can improve quality of IT services and consequently consumption would improve alongside reduced uncertainty.

\subsection{Proposition 2: Comparison of the Cost Center to the First Best Benchmark}

(i) Cost center quality is always lower than benchmark quality; and (ii) Cost center consumption is greater than benchmark consumption when the fixed cost of quality is sufficiently high,

$$
a>\frac{\alpha\left(\begin{array}{l}
3(\beta-\alpha)(2 c \beta-k) \\
-(2 \alpha-1) \varepsilon^{2}
\end{array}\right)+\sqrt{\left(\begin{array}{l}
9 k^{2} \alpha(\beta-\alpha)^{2}+6 c(2 \alpha-1) \\
(\beta-\alpha)(k(2 \beta-\alpha)-2 c \alpha \beta) \varepsilon^{2}+c^{2}(2 \alpha-1)^{2} \alpha \varepsilon^{4}
\end{array}\right)}}{12 c \alpha^{2}} .
$$

Proposition 2 compares quality and consumption under the cost center structure to the benchmark results. The superior quality of the benchmark solution is intuitive because the benchmark solution has pricing set to marginal cost to eliminate deadweight loss. Such pricing enables improvement in quality. However, it is not readily intuitive that consumption under the cost center can exceed that of the benchmark solution. We find that when the fixed cost of quality is sufficiently high, cost center consumption exceeds benchmark consumption. The reasoning is that the benchmark solution, with pricing, is unable to increase quality sufficiently high to drive consumption whereas the cost center offers its services and the corresponding IT service quality as a free resource, which drives up consumption of IT services. Figure 1 illustrates the differences in behavior in consumption of IT services with respect to the fixed cost of quality parameter.

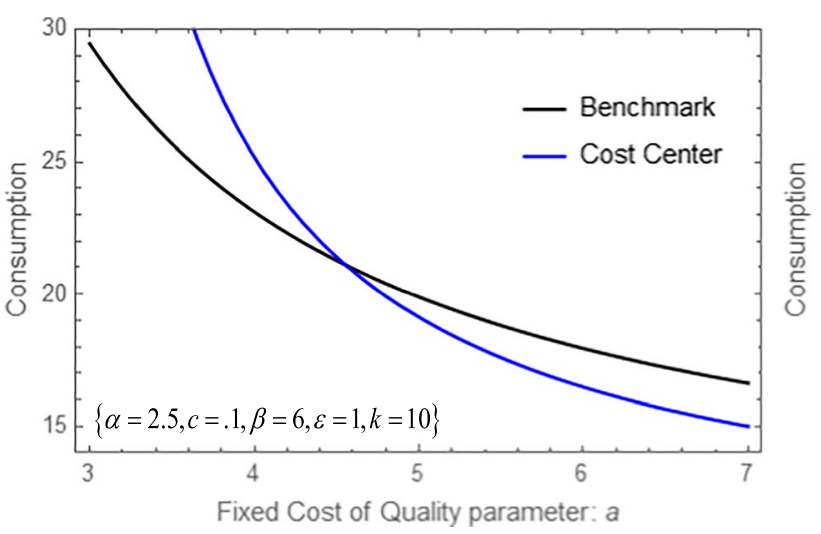

Fig. 1 Consumption of IT services with respect to the fixed cost of quality parameter $a$

\section{IT Department Organized as a Profit Center}

In contrast to the cost center organizational structure, under the profit center organizational structure the IT department determines the price and quality of IT services to maximize its profits under the profit center. Recall from the Model section that the IT department is perfectly informed about IT costs but is imperfectly informed about the demand for IT services. Therefore, the uncertainty parameter is $\varepsilon=0$ for IT costs. The IT department generates a profit $S_{I T}=(x \cdot p)-C_{I T}$, and the surplus generated by the functional unit is $S_{U}$. The benefit to the firm is $S_{f}=\left(S_{U}+S_{I T}\right)$. The cost of providing IT services is $C_{I T}=x(c+q)+a \cdot q^{2}+F$. Because price and quality are determined by the IT department, its optimization problem is $\operatorname{Max}_{p, q}\left\{S_{I T}\right\}$. The IT department's optimization leads to the following proposition.

\subsection{Lemma 3: Interior Solution for IT Department as a Profit Center}

Under the profit center organizational structure, the IT department determines the optimal quality and price of IT services to be: $p^{* P C}=\frac{2 a(k+c \alpha)-(\beta-\alpha)(c \beta-k)}{4 a \alpha-(\beta-\alpha)^{2}}, q^{* P C}=\frac{(k-c \alpha)(\beta-\alpha)}{4 a \alpha-(\beta-\alpha)^{2}}$, the benefit to the firm is: $S_{f}^{* P C}=\frac{a(k-c \alpha)^{2}\left(6 a \alpha-(\beta-\alpha)^{2}\right)}{\left(4 a \alpha-(\beta-\alpha)^{2}\right)^{2}}-F$, and the consumption of IT services is: $x^{* P C}=\frac{2 a \alpha(k-c \alpha)}{4 a \alpha-(\beta-\alpha)^{2}}$.

Lemma 3 reports the optimal price and quality that the IT department will offer under a profit center structure. The optimal quality and price are non-negative in the interior. The price for IT services is greater than the marginal cost of providing the services, therefore there will be some deadweight loss. The proof is available in Appendix 1. 


\subsection{Proposition 3: Comparison of the Profit Center to the First Best Benchmark}

The First Best solution provides: (i) greater firm benefit, (ii) higher quality of IT services, and (iii) lower price of IT services, compared to the profit center.

Proposition 3 compares the first best solution to the profit center and the results support the intuitive notion that the benchmark solution is superior in firm benefit while providing lower prices and higher quality. The proof is in Appendix 1.

\section{Comparison of Organizational Structures}

We compare the two organizational structures developed in the previous two sections to analyze the differences and understand the conditions when one structure may be preferred over the other. The firm determines the preferred organizational structure for the IT department by comparing the net benefits from IT that the firm expects to realize from each organizational structure. The preferred organizational structure for the IT department is the structure that offers greater benefits to the firm from the consumption and use of IT services.

\subsection{Proposition 4: Comparison of Quality of IT Services between Organizational Structures}

The cost center organizational structure supports higher quality of IT services in the interior if and only if the demand intercept is sufficiently high, $k>\frac{c \alpha\left(6 a \alpha(\alpha+\beta)-(\beta-\alpha)\left(3 \alpha \beta+(2 \alpha-1) \varepsilon^{2}\right)\right)}{(\beta-\alpha)\left(6 a \alpha-3 \alpha^{2}+(2 \alpha-1) \varepsilon^{2}\right)}$

The finding in Proposition 4 that the cost center can offer greater quality than a profit center is interesting because prior literature (Allen, 1987) has argued that the profit center offers higher quality. Intuitively, one would expect higher quality of IT services under profit center because IT services are priced for profit maximization under the profit center structure, whereas under the cost center structure IT services are free and increasing the quality of IT services will lead to even greater consumption causing further increase in efficiency losses under the cost center structure.

To understand the result in Proposition 2, note that increasing quality also provides benefit to the consuming unit and higher levels of consumption under the cost center structure enable the fixed cost of quality to be spread over a larger base of consumption of IT services. The lowest quality viable level is nominally set to zero in the model. Therefore, in our model, the intercept clearly determines consumption that would take place at this base level of quality and when price is zero. Proposition 2 finds that this base

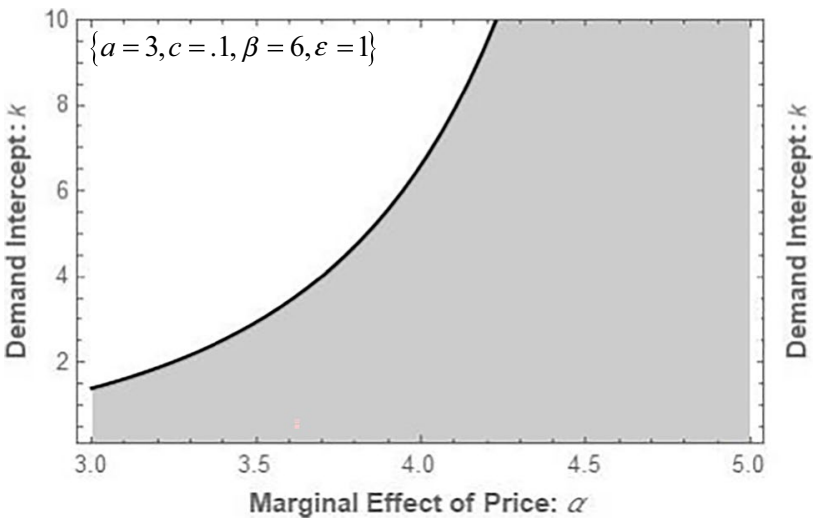

Fig. 2 Comparison of quality of IT services

level of consumption defined by the intercept of the demand function must be sufficiently large for the cost center to offer higher quality than the profit center. Intuition suggests that higher values for a base level of consumption represents higher levels of demand for IT services at the minimum level of quality and zero price. Hence, under the cost center organizational structure, the IT department can offer higher quality of IT services compared to the profit center structure, when the base level of demand is sufficiently large.

As an example, consider a new IT service such as a Business Intelligence (BI) software application that can be enhanced in quality by providing data science consulting and analytical services. The base level of quality which is simply providing access to the BI software with no additional support or services is expected to have high demand which is captured by the demand intercept $(k)$. Proposition 2 predicts that the firm will provide higher quality under the cost center compared to the profit center, perhaps by providing the additional support of data science consulting and analytical services. Figure 2 illustrates the result from Proposition 2 along with the impact of price. The proof is in Appendix 1 .

\subsection{Proposition 5: Comparison of Consumption of IT Services between Organizational Structures}

When the fixed cost of quality is sufficiently low, $a<\frac{Y_{1}+\sqrt{Y_{2}}}{12 \alpha^{2}(k+c \alpha)}$, the profit center generates higher consumption of IT services than the cost center structure in the interior, where $Y_{1}$ and $Y_{2}$ are as defined in Appendix 1.

The result from Proposition 5 is interesting because Gurbaxani and Kemerer (1989) and Jensen and Meckling (1998) make the argument that the cost center organizational structure, where services are provided at no charge to the user, will lead to higher consumption and that the profit center structure will lead to lower consumption. Intuitively, consumption of IT services will be higher when such services 


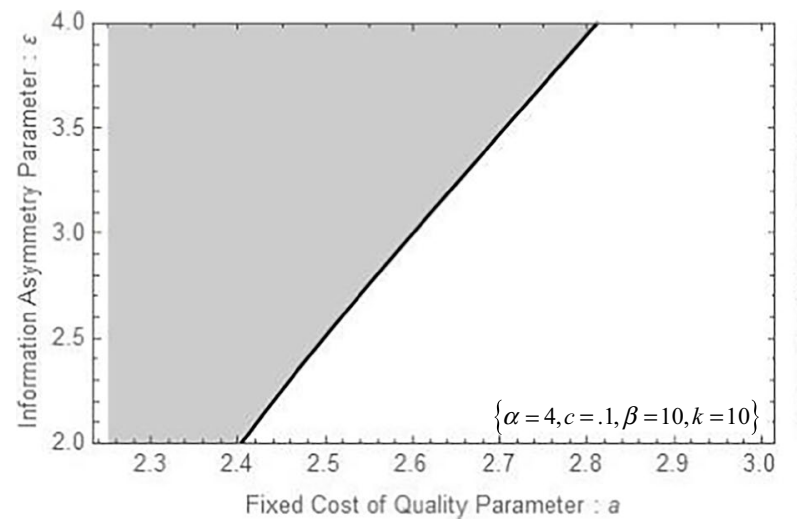

Fig. 3 Comparison of consumption of IT services

are available for free when compared to demand when IT services have a price.

We find that in most settings, conventional wisdom and the findings from prior literature hold such that the cost center has greater consumption than the profit center. However, Proposition 3 identifies an interesting region where this result is reversed so that the profit center organizational structure has greater consumption than the cost center structure. This surprising result can be understood by noting that, the profit center sometimes offers much higher quality of IT services than the cost center. Such higher quality of IT services will lead to higher consumption ceteris paribus. Even when price increases, there may be a net increase in consumption because the quality of IT services under the profit center structure is high. When the fixed cost of quality is sufficiently low, the quality of IT services under the profit center structure is so much higher than quality under the cost center structure that it leads to higher consumption of IT services. Figure 3 illustrates the proposition. The proof is in Appendix 1.

\subsection{Proposition 6: The Preferred IT Organizational Structure}

The profit center organizational structure is preferred over the cost center structure: (i) If and only if the fixed cost of IT quality is sufficiently low, $a<a_{1}$, where $a_{1}$ is as defined in Appendix 1; or (ii) If and only if the marginal cost of IT is sufficiently high, $c>c_{1}$ where $c_{1}$ is as defined in Appendix 1 .

The first part of Proposition 6 reports the role of fixed cost of quality in determining the preferred organizational structure for the IT department. The first part shows that low fixed cost of quality favors the profit center organizational structure for the IT department. Our result is in contrast with Wang and Barron (1995) who find that the cost center is always preferred because the information rent under the profit center organizational structure is never lower than the loss of value

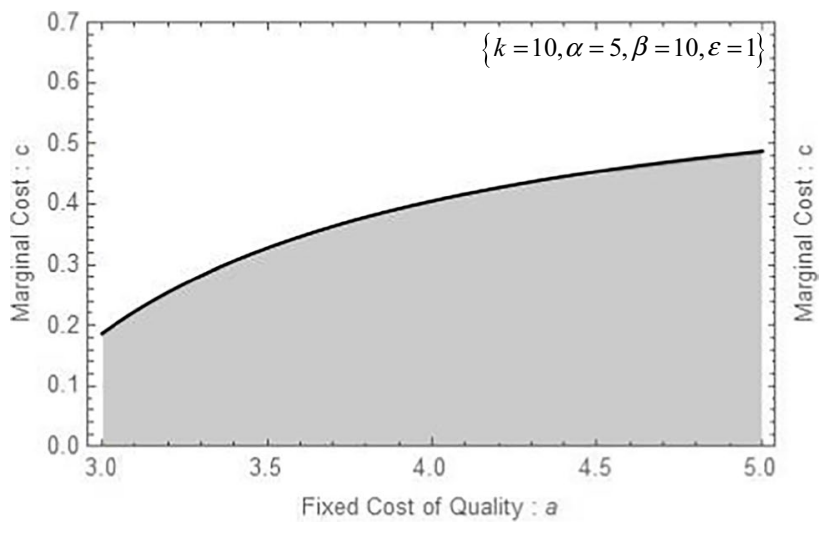

Fig. 4 Preferred IT organizational structure

from information asymmetry under the cost center structure in their model. They incorporate information asymmetry with respect to cost of IT services whereas we include both cost and demand information asymmetry. Furthermore, we include quality of IT services as a decision variable in our model whereas Wang and Barron (1995) do not include quality.

To explain the intuition for our result, we note that the profit center generally offers higher quality of IT services. When the fixed cost of quality is sufficiently low under the profit center organizational structure, the IT department can increase profits by substantially increasing the quality of IT services. Such higher quality IT services under the profit center structure leads to increased surplus for the functional unit. Consequently, both IT profits and functional unit surplus are higher under the profit center organizational structure. Hence, the firm determines that the profit center organizational structure is the preferred structure for the IT department.

The second part of proposition 4 considers the marginal cost of IT. When the IT department is organized as a cost center, IT services are offered at no charge to the IT-consuming functional unit and these services are consumed even when the marginal cost exceeds the benefit to the firm. Consequently, the firm incurs a loss on each unit from such inefficient consumption. The magnitude of the loss from inefficient consumption is greater when marginal costs are higher. In contrast, the profit center is able to restrain consumption by pricing IT services such that the profit center organizational structure is the preferred structure when marginal costs are high. This is illustrated in Fig. 4. The proof is in Appendix 1.

\subsection{Corollary 1: Demand Uncertainty and Preferred Structure}

The difference in firm benefits between the profit center and the cost center increases with increasing information asymmetry: $\left(\frac{\partial S_{f}^{* P C}}{\partial \varepsilon}-\frac{\partial S_{f}^{* C C}}{\partial \varepsilon}\right)>0$. 

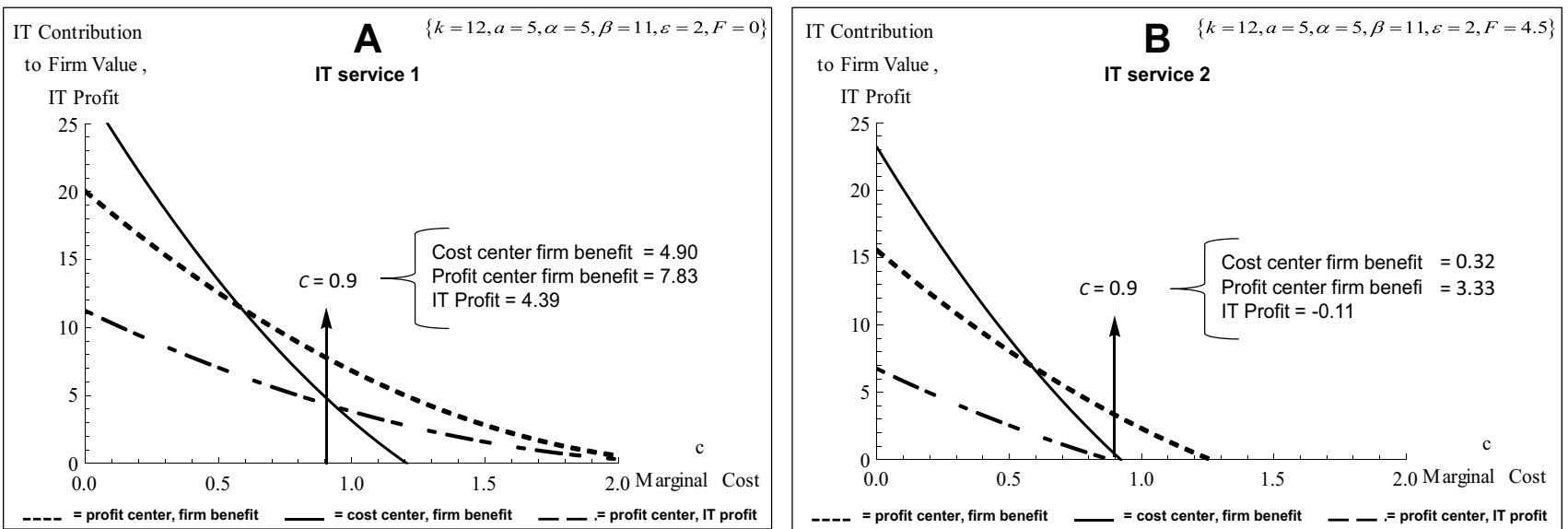

Fig. 5 Variety of IT service example

Corollary 1 suggests that when there is increasing information asymmetry captured through the uncertainty of demand and cost under the cost center structure, the profit center is likely to be the preferred governance structure for the firm. This result stems from Proposition 1 which shows that increasing information asymmetry decreases benefits to the firm under the cost center structure and quality is simultaneously decreasing. Note that the profit center uncertainty is only in demand for IT services because the IT department knows its IT costs. The proof is in Appendix 1.

\section{Effect of Organizational Structure on Variety of Services}

Up to this point, we have assumed that the IT department provides only one service. As noted in the introduction, this paper introduces a novel feature of variety of IT services. In this section, we develop an extension to analyze the number of IT services that would be offered under each organizational structure. Interestingly, we find that sometimes the organizational structure that is not preferred by the firm may offer more IT services than the preferred structure (Proposition 6). This non-intuitive result is explained by examining the difference in the optimization decisions under the two organizational structures. Under the cost center, the firm maximizes expected benefit to the firm from IT services. Whereas, under the profit center structure, the IT department maximizes its own profits. However, the preferred organizational structure for the IT department is always chosen such as to maximize benefit to the firm from IT services.

We extend the model to consider the set of IT services that could be offered by the IT department. We characterize this set by a maximum of $\psi$ IT services that could be offered under either organizational structure. We make simplifying assumptions on the nature of the IT services in order to keep the analysis mathematically tractable. Each IT service $i \in[1, \psi]$ provides surplus to the IT-consuming functional unit and each IT service is subject to the same demand and cost characteristics described in the model section. To simplify analysis we assume the services are differentiated only in their fixed cost $F_{i}, \quad i=1,2, \ldots, \psi$. Therefore, $\psi$ IT services can be ordered such that $S_{f i}(\cdot)>S_{f i+1}(\cdot), i=1,2, \ldots, \psi$ and $S_{I T i}(\cdot)>S_{I T i+1}(\cdot), i=1,2, \ldots, \psi$ in the feasible region.

Under the cost center organizational structure, the firm maximizes benefits from IT services $\left(\sum_{i=1}^{n} S_{f i}^{C C}(\cdot)\right)$ by providing only those services that yield positive net benefits to the firm. Therefore the optimal number of services $n$ under the cost center structure must be such that $S_{f n}(\cdot) \geq 0$ and $S_{f n+1}(\cdot)<0$. Under the profit center organizational structure, the IT department offers only those services that yield positive profit to the IT department. Therefore the optimal number of services $m$ under the profit center structure must be such that $S_{I T m}(\cdot) \geq 0$ and $S_{I T m+1}(\cdot)<0$, and the maximum profit for the IT department is $\left(\sum_{j=1}^{m} S_{I T j}(\cdot)\right)$. The benefit to the firm under the profit center will be $\left(\sum_{j=1}^{m} S_{f j}^{P C}(\cdot)\right)$.

The organizational structure for the IT department that provides greater total net benefit to the firm (sum of net benefit from each IT service) from IT services is the preferred organizational structure. In this section, we examine whether the preferred organizational structure for the IT department provides a greater number of IT services. We begin with a illustrative example of two different IT services as shown in Fig. 5, that meet the ordering condition. These services are denoted as IT Service 1, and IT service 2. We determine the preferred organizational structure and the optimal number of services that will be offered using a marginal cost of $c=0.9$. This case $(c=0.9)$ is interesting because the cost 
center organizational structure will offer greater number of IT services even though the profit center is the preferred structure.

We begin by determining the services offered under each organizational structure. Under the profit center structure, the IT department will only offer IT Service 1 (Fig. 5A), which generates positive IT profit $\left(S_{I T i}(\cdot)=4.39>0, i=1\right)$, whereas IT Service 2 generates negative profit to the IT department $\left(S_{I T i}(\cdot)=-0.11<0, i=2\right)$ as shown in Fig. 5B. It is interesting to note that IT Service 2 generates positive benefit to the firm $\left(S_{f i}^{C C}(\cdot)=3.33>0, i=2\right)$, yet IT Service 2 will not be offered by the IT department under the profit center governance structure.

The firm would offer both IT services under the cost center organizational structure, as seen from Fig. 5A and B because each of these services provides net positive benefit to the firm $\left(S_{f 1}^{C C}(\cdot)=7.83>0, S_{f 2}^{C C}(\cdot)=3.33>0\right)$. To determine the preferred organizational structure we compare the total benefit to the firm from all offered services under each organizational structure. The profit center structure offers one less IT service than the cost center structure, and generates a benefit of 7.83, whereas the cost center structure offers both IT services, generating a total benefit of 5.16. Hence, the profit center is the preferred governance struc$\operatorname{ture}\left(\sum_{j=1}^{1} S_{f j}^{P C}(\cdot)=7.83>\sum_{i=1}^{2} S_{f i}^{C C}(\cdot)=4.83+0.33=5.16\right)$, but it offers fewer IT services than the cost center structure. This condition can occur when the net benefit to the firm from each service under the profit center is sufficiently larger than the net benefit under the cost center structure. Note that the converse, where a cost center organizational structure is preferred, but offers fewer IT services than a profit center structure, cannot occur.

\subsection{Proposition 7: Preferred IT Organizational Structure and Variety of IT Services}

When the profit center is the preferred organizational structure, and the marginal cost is: $c<c_{v}$, then the cost center structure offers a greater variety of IT services than the profit center structure, where $c_{v}$ is as defined in Appendix 1. When the cost center is the preferred organizational structure, the profit center will never offer greater number of IT services than the cost center.

Proposition 7 is the formal statement of this interesting result that when the profit center is the preferred structure that generates greater benefits to the firm from IT services, this structure may not offer the greatest variety of IT services.

The intuition behind this result can be understood by examining the difference in the decision maker and the decision rule under each organizational structure. Under the cost center structure, the IT department decides which
IT services will be offered, whereas under the profit center, the firm decides which IT services will be offered. The IT department uses positive IT profits as the decision rule for offering an IT service whereas the firm uses net benefit as the decision rule for offering an IT service. It is possible that under the profit center structure, the IT department will not offer an IT service even when that IT service offers a positive net benefit to the firm because IT profit from that service is negative. In such a situation, under the profit center structure, the IT department will offer fewer services than offered under the cost center structure. However, the profit center can still be the preferred organizational structure because each service offered by the profit center generates greater net benefit to the firm compared to the benefit that would be generated under the cost center structure. Therefore, the cumulative benefit to the firm from IT services generated under the profit center structure can be greater than that generated under the cost center structure, even when there are fewer services offered by the IT department under the profit center structure. Hence, the profit center can be the preferred organizational structure for the IT department, and yet offers fewer services than under a cost center structure.

On the other hand, when the cost center organizational structure is preferred for the IT department, the profit center structure will not offer greater number of IT services. The intuition behind this result is that under the profit center structure, the IT department will not offer a service even when there is benefit to the firm from offering that service because IT department profit from that service is negative. In contrast under the cost center structure an IT service will be offered as long as there is a benefit to the firm. Under our IT service ordering assumption, for any given marginal cost, all services are ordered in terms of decreasing benefits. When the cost center is the preferred structure, the benefit to the firm under the cost center structure must be greater than IT department profit under the profit center structure. Hence, any IT service offered under the profit center structure will also be offered under the cost center structure. Therefore, the profit center structure can never offer greater number of services when the preferred organizational structure is the cost center. The proof is provided in Appendix 1.

\subsection{Proposition 8: Uncertainty and Variety under the Profit Center}

The marginal cost threshold for variety from proposition 8 , $c_{v}$ is decreasing with uncertainty, $\frac{\partial c_{v}}{\partial \varepsilon}<0$.

Proposition 8 finds that increasing uncertainty drives the marginal cost $c_{v}$ lower. When this result is applied to the result from Proposition 7 the consequence is that when the profit center is the preferred governance structure, the likelihood of the cost center offering more services will decrease with uncertainty. Hence, increasing uncertainty increases 
the likelihood that the preferred structure will offer greater variety of IT services. The practical implication is that new and emerging complex IT services with high levels of support such as business intelligence, analytics services, or machine learning applications are likely to come with high uncertainty in demand and cost. Furthermore, such services that arise from new technological developments are likely to be accompanied by high marginal costs at least in early incarnations. This in turn increase the likelihood that the marginal cost of the new service is greater than the threshold $c_{v}$ and Proposition 8 would suggest that such new services are more likely to be offered under the profit center structure.

\section{Discussion}

Our paper provides a model and framework to analyze whether the IT department should be organized as a cost center or as a profit center. Prior literature has made qualitative arguments regarding the benefits to the firm from the choice of organization structure. We build on this literature by developing an analytical model to compare the performance of the cost center and the profit center structure for the IT department, and to identify conditions that are suited for each structure. Our analysis examines the impact of IT service quality, consumption and variety of IT services to generate several interesting results.

DeLone and McLean (2003) highlight the importance of quality of IT services as an important factor for generating benefits to the firm. Prior literature (Allen, 1987) has argued that the profit center will offer higher quality of IT services. Therefore, some firms may adopt the profit center structure under the belief that it provides higher quality services than the cost center structure. However, our new finding shows that under certain conditions the cost center structure will provide higher quality of IT services. Thus, firms need to give careful consideration to the IT organizational structure instead of relying on commonly held beliefs. Weinzimer (2015) provides examples such as Valspar and Synopsys who improved the quality of IT services and thereby improved business value and business performance by the use of metrics, dashboards, and by communicating value to the users.

DeLone and McLean (2003) have also highlighted the importance of variety of IT services as another important factor. An intuitive notion that has not been previously analyzed is that the preferred organization structure will offer a greater variety of IT services. However, we show that the cost center organizational structure provides a greater variety of IT services even when it is not the preferred structure. This occurs because under the profit center structure, the IT department may not offer certain services even when these IT services benefit the firm because they are unprofitable to the IT department. In contrast, under the cost center structure, all services that generate net benefit to the firm are offered. Weinzimer (2015) also notes that the IT department which is a cost center at Synopsys was able to create better products and services which implies more variety.

We show that the notion from prior literature that "free" IT services drive higher consumption under the cost center structure does not always hold. Gurbaxani and Kemerer (1989) point out that the cost center organizational structure leads to overconsumption of IT services. While this paper lends analytical support to this propensity, we find that there are conditions when the converse is true: the profit center structure generates higher consumption of IT services compared to the cost center structure. This can be explained by the quality differential in IT services between the profit center structure and the cost center structure. When the profit center service quality is sufficiently larger than the cost center quality, it leads to higher consumption of IT services under the profit center structure.

We find that there is no universally dominant organizational structure such as suggested in Wang and Barron (1995) where the cost center structure is always preferred. Our results show that the profit center is the preferred structure when the fixed cost of quality for IT services is low, and the cost center is the preferred structure when marginal cost for IT services is low.

The results have several managerial implications. Our findings suggest that the IT department should offer lower quality services when demand and correspondingly, IT cost has high uncertainty, such as when offering a new IT service to its internal functional units. Social media marketing is a new phenomenon and many firms are just entering this realm of customer interaction. For example HootSuite offers a social media dashboard and TweetDeck (acquired by Twitter) offers a real-time Twitter tool to help firms track and evaluate customer engagement. When such services are offered by the IT department under the cost center organizational structure the demand and cost for these new services may be characterized by high uncertainty. Our results suggest that the firm should err on the side of offering lower quality, at least until the uncertainties are mitigated. Quality in this example may be characterized by limited availability or limited training and support for the deployment of these services for customer engagement and targeted marketing.

Our results suggest that firms should consider the cost center organizational structure for IT services that are characterized by low marginal cost. For example, ubiquitous office PC maintenance and software upgrades or updates would fit this characterization. Similarly, office productivity applications software and related support would also fit this characterization. Another example could be private computer networks, where the marginal cost of network communication is low after the network has been commissioned. 
Complex IT services that require a high level of support from IT personnel will incur high marginal cost. For example, frequent executive requirements for customized business reports may require SQL generation tools and personnel for database and data warehouse support. Our results suggest that such services should be offered under the profit center organizational structure. As a second example, a product division may require customized IT services for training field personnel on a new product where such training will improve the productivity of the sales team. Such, customized IT services are characterized by high marginal cost because of customization and personnel support. Our analysis suggests that these services should be offered under the profit center organizational structure.

Our result on variety suggest that a firm may need to offer or fund some services as a corporate service even when the IT department is operated as a profit center. This implies a hybrid structure where IT services with certain characteristics such as high marginal cost are offered under the profit center whereas others are offered under the cost center structure. Under the profit center structure, the IT department will not offer unprofitable IT services that are beneficial to the firm. Examples of such services could include maintenance and support for specialized workstations or peripherals that are not widely used within the firm. Therefore, the IT department may find it unprofitable to offer these services even though they generate benefit to the firm.

The analytical modeling methodology employed abstracts key elements of benefits to business from organizational structure. Hence, the model and analysis are limited by the variables and constructs employed in such an abstraction and is therefore imperfect and limited, and will not capture every possible state or contingency that a firm encounters, which are theoretically infinite. Nevertheless, models ae useful to capture, explain and analyze observed phenomena even though they are limited and imprecise replications (Box, 1976).

Our research questions analyzed are relevant because rapid technological change is a defining characteristic of IT. Today we are witnessing the emergence of Social, Mobile, Analytics and Cloud (SMAC) and the Internet-of-Things (IoT) which can affect organizational structure (Porter \& Heppelmann, 2015). Based on our results, firms may need to consider a transition in the organization structure of the IT department or for individual IT services, when faced with significant change in the cost or demand for such IT services. A suboptimal organizational structure could have significant impact on the benefits derived from IT particularly because IT spending is the largest portion of non-residential spending (Colecchia \& Schreyer, 2002). The importance of quality, consumption and variety of IT services has been shown to be important in generating benefits to the firm (Delone \& McLean, 2003). We show that organizational structure affects these important attributes of quality and variety.

\section{Appendix 1}

List of variables and parameters

Proofs

\section{List of variables and parameters}

\section{Proofs}

\section{Proof of Lemma 1: First Best benchmark solution under perfect information}

In the first best solution, the firm is perfectly informed about demand and cost. Hence, the firm sets the price equal to marginal cost, and optimizes quality to generate the optimal surplus without any deadweight loss.

$$
\begin{gathered}
\operatorname{Max}_{p, q}\left\{S_{f}^{F B}\right\}=\operatorname{Max}_{p, q}\left\{S_{U}^{F B}+S_{I T}^{F B}\right\} \\
=\operatorname{Max}_{p, q}\left\{\left(\frac{(k-p \alpha+q \beta)^{2}}{2 \alpha}\right)^{+}+\left(p(k-p \alpha+q \beta)-(c+q)(k-p \alpha+q \beta)-a q^{2}\right)\right\}
\end{gathered}
$$

The solution to the firm's optimization problem results in the following optimal First Best price and quality:

$q^{* F B}=\frac{(k-c \alpha)(\beta-\alpha)}{2 a \alpha-(\alpha-\beta)^{2}}, \quad p^{* F B}=\frac{2 a c \alpha+(\beta-\alpha)(k-c \beta)}{2 a \alpha-(\alpha-\beta)^{2}}$

It is readily seen that price is set to marginal cost. Substituting the expressions in (7) into the respective functions, we obtain:

$S_{f}^{* F B}=\frac{a(k-c \alpha)^{2}}{2 a \alpha-(\beta-\alpha)^{2}}-F, \quad x^{* F B}=\frac{2 a \alpha(k-c \alpha)}{2 a \alpha-(\beta-\alpha)^{2}}, \quad S_{U}^{* F B}=2 \alpha\left(\frac{a(k-c \alpha)}{2 a \alpha-(\beta-\alpha)^{2}}\right)^{2}$

Concavity Condition Concavity requires the determinant of the Hessian of the objective function (6) to be positive and we have $2 a \alpha-(\beta-\alpha)^{2}>0$. We also require the first element of the Hessian matrix to be negative and we have $\beta^{2}-2 \alpha(a+\beta)<0$.

Positive Price Setting price in (7) to be positive results in the requirement $k>c(\beta-2 a \alpha /(\beta-\alpha))$,

Positive Quality Setting quality in (7) to be positive results in the requirement $k>c \alpha$ and $(\beta>\alpha)$.

This completes the proof. 
Table 2 List of variable and parameters under the linear demand model

\begin{tabular}{ll}
\hline Symbol & Description \\
\hline$p$ & price for IT services from the inverse demand function \\
$x$ & quantity of IT service consumed by functional unit \\
$q$ & quality of IT service \\
$c$ & marginal cost of IT services \\
$a$ & fixed cost of quality of IT services parameter \\
$F$ & fixed cost of IT services independent of quality and consumption \\
$\alpha$ & marginal effect of price on demand for IT services \\
$\beta$ & marginal value of quality of IT service to functional unit \\
$k$ & demand intercept: quantity consumed at zero price and base quality \\
$\tilde{\gamma}$ & random variable representing demand and cost uncertainty \\
$\varepsilon$ & distribution parameter for uncertainty \\
$\psi$ & maximum variety of IT services offered \\
$C_{I T}$ & cost of IT services \\
$S_{U}$ & functional unit surplus from use of IT services \\
$S_{I T}$ & IT department profit \\
$S_{f}$ & surplus to the firm, or firm benefit from the use of IT services by \\
& functional unit \\
\hline
\end{tabular}

\section{Proof of Lemma 2: Interior solution for IT department as a cost center}

Because of information asymmetry, the firm is imperfectly informed of the demand and cost parameters and observes $(\beta+\tilde{\gamma})$ and $(a+\tilde{\gamma})$ where $\tilde{\gamma}$ has a Uniform distribution $U(-\varepsilon, \varepsilon)$. For notational simplicity we define $\hat{\beta} \equiv(\beta+\tilde{\gamma})$ and $\hat{a} \equiv(a+\tilde{\gamma})$. Therefore $\hat{\beta} \sim U(\beta-\varepsilon, \beta+\varepsilon)$ and $\hat{a} \sim U(a-\varepsilon, a+\varepsilon)$. The firm incurs a marginal cost $(c+q(1+\tilde{\gamma}))$. Price of IT services is not a decision variable and nominally set to zero. The firm computes expected surplus generated by the functional unit when it sets quality of IT services to be $q^{* C C}$ as follows:

$S_{U}^{C C}=\int_{0}^{\left(k+\hat{\beta} q^{* C C}\right)} \frac{\left(k+\hat{\beta} q^{* C C}-x\right)}{\alpha} d x=\frac{\left(k+\hat{\beta} q^{* C C}\right)^{2}}{2 \alpha}$

The firm's net benefit from IT services is the surplus in (9) less the cost of IT. The firm maximizes the expected net benefit from IT. which is $E\left[S_{f}^{C C}\right]=E\left[S_{U}^{C C}-\left(x M C_{I T}+F C_{I T}\right)\right]$.

$E\left[S_{f}^{C C}\right]=E\left[\left(S_{U}^{C C}-C_{I T}\right)\right]=E\left[\frac{\left(k+\hat{\beta}_{q}^{* C C}\right)^{2}}{2 \alpha}-\left(x^{c C}\left(c+q^{* C C}(1+\tilde{\gamma})\right)+\hat{a}\left(q^{* C C}\right)^{2}+F\right)\right]$
$x^{c C}=k+\hat{\beta} q^{* C C}$

We generate expected firm benefit by applying the probability density function (pdf) of the random variables $\hat{\beta}, \hat{a}, \tilde{\gamma}$, and integrating (10) as follows:
$E\left[S_{f}^{C C}\right]=\int_{-\varepsilon}^{\varepsilon}\left(\int_{a-\varepsilon}^{a+\varepsilon}\left(\int_{\beta-\varepsilon}^{\beta+\varepsilon}\left(S_{f}^{C C}\right)\left(\frac{1}{2 \varepsilon}\right) d \hat{\beta}\right)\left(\frac{1}{2 \varepsilon}\right) d \hat{a}\right) d \tilde{\gamma}$

Substituting (10) in (11), the firm's problem can be stated as follows:

$\left.\operatorname{Max}_{q^{* C C}}\left\{\int_{-\varepsilon}^{\varepsilon} \int_{a-\varepsilon}^{a+\varepsilon} \int_{a-\varepsilon}^{\beta+\varepsilon}\left(\int_{\beta-\varepsilon}^{C C}\left(\frac{1}{2 \varepsilon}\right) d \hat{\beta}\right)\left(\frac{1}{2 \varepsilon}\right) d \hat{a}\right) d \tilde{\gamma}\right\}$

Solving the first order condition generated by (12) we obtain optimal quality:

$q^{* C C}=\frac{3(k(\beta-\alpha)-c \alpha \beta)}{6 \alpha(a+\beta)-3 \beta^{2}+(2 \alpha-1) \varepsilon^{2}}$ 
Substituting optimal quality into the demand function, into the functional unit surplus, and into the firm benefit expression, we obtain the following results:

$$
\frac{6 a c \alpha^{3}+(\beta-\alpha)\left(k\left(3 \alpha^{2}+(2 \alpha-1) \varepsilon^{2}\right)-c \alpha\left(3 \alpha \beta+(2 \alpha-1) \varepsilon^{2}\right)\right)}{\left(2 a \alpha-(\beta-\alpha)^{2}\right)\left(6 \alpha(a+\beta)-3 \beta^{2}+(2 \alpha-1) \varepsilon^{2}\right)}
$$

Concavity Condition The second derivative of the objective function (12) is $-\left(6 \alpha(a+\beta)-3 \beta^{2}+(2 \alpha-1) \varepsilon^{2}\right) / 3 \alpha$ and concavity requires that the determinant is negative. Therefore, the denominator of (13) for the optimal quality, $6 \alpha(a+\beta)-\left(3 \beta^{2}+\varepsilon^{2}\right)$ is positive. This in turn requires $\alpha>(3$ $\left.\beta^{2}+\varepsilon^{2}\right) / 2\left(3(a+\beta)+\varepsilon^{2}\right)$, or alternatively $a>\frac{3 \beta(\beta-2 \alpha)-(2 \alpha-1) \varepsilon^{2}}{6 \alpha}$. Additionally, if there is no bound placed on $\varepsilon$, it is necessary that $\alpha>1 / 2$.

Positive Quality Setting (13) to be positive results in the requirement $\beta>k \alpha /(k-c \alpha), k>c \alpha \beta /(\beta-\alpha)$, or $\alpha<k \beta /$ $(k+c \beta)$.

This completes the proof.

\section{Proof of Proposition 1: Effect of information asymmetry on quality and consumption of IT services}

Taking the partial derivative of (13) with respect to $\varepsilon$ which is $\partial q^{* C C} / \partial \varepsilon$, simplifying and rearranging terms, we obtain the result $\frac{\partial q^{* C C}}{\partial \varepsilon}=-\frac{6(2 \alpha-1)(k(\beta-\alpha)-c \alpha \beta) \varepsilon}{\left(6 \alpha(a+\beta)-3 \beta^{2}+(2 \alpha-1) \varepsilon^{2}\right)^{2}}$. The denominator is always positive, and from the feasibility requirements in the Proof of Lemma 2 it is readily seen that the numerator is also positive and we have $\frac{\partial q^{*} C C}{\partial \varepsilon}<0$.

Similarly, taking the partial derivative of $S_{U}^{* C C}$ from (14) with respect to $\varepsilon$ which is $\partial S_{U}^{* C C} / \partial \varepsilon$, simplifying rearranging terms and substituting the expression for $x^{* C C}$ from (14) we obtain the result $\frac{\partial S_{U}^{* C C}}{\partial \varepsilon}=-\frac{6(2 \alpha-1) \beta(k(\beta-\alpha)-c \alpha \beta) \varepsilon}{\left(6 \alpha(a+\beta)-3 \beta^{2}+(2 \alpha-1) \varepsilon^{2}\right)^{2}}$. The numerator and denominator are always positive and we have $\frac{\partial S_{U}^{* C C}}{\partial \varepsilon}<0$.

This completes the proof.

\section{Proof of Proposition 2: Comparison of the cost center to the First Best benchmark}

(i) We compare quality by taking the difference between the first best quality and cost center quality of IT services $\left(q^{* F B}-q^{* C C}\right)$ which results in the following expression:
Imposing the feasibility conditions from the proof of Lemma 2 on (15) requires that the difference is positive and we have $\left(q^{* F B}-q^{* C C}\right)>0$.

(ii) We compare consumption by taking the difference between the cost center and first best consumption of IT services $\left(x^{* C C}-x^{* F B}\right)$. Solving this difference for the fixed cost of quality parameter $(a)$ we generate two quadratic roots:

$\left(\frac{1}{12 c \alpha}\right)\left(\begin{array}{l}-\left(3(\beta-\alpha)(k-2 c \beta)-c(2 \alpha-1) \varepsilon^{2}\right) \pm \\ \sqrt{\left(\frac{(\beta-\alpha)\left(9 k^{2} \alpha(\beta-\alpha)-6 c(\alpha(k+2 c \beta)-2 k \beta)(2 \alpha-1) \varepsilon^{2}\right)}{\alpha}+c^{2}(2 \alpha-1)^{2} \varepsilon^{4}\right)}\end{array}\right)$

Testing the negative root of (16) for a positive value results in the requirement that $k<\frac{3 c \alpha \beta^{2}}{3 \alpha \beta+(2 \alpha-1) \varepsilon^{2}}$ which requires that $k<c \alpha$, which is a contradiction. Therefore, we have

$a>\left(\begin{array}{l}\left(12 a c \alpha+3(\beta-\alpha)(k-2 c \beta)+c(2 \alpha-1) \varepsilon^{2}\right) \\ +\sqrt{9 k^{2}(\beta-\alpha)^{2}+\frac{6 c(2 \alpha-1)(\beta-\alpha)(k(2 \beta-\alpha)-2 \alpha \beta \beta)(2 \alpha-1) \varepsilon^{2}}{\alpha}+c^{2}(2 \alpha-1)^{2} \varepsilon^{4}}\end{array}\right)$

Directionality can readily be checked numerically and we have $\left(x^{* C C}-x^{* F B}\right)>0$ when (17) is true.

This completes the proof.

\section{Proof of Lemma 3: Interior solution for IT department as a profit center}

The IT department sets optimal price and quality where expected profit is expressed as follows:

$S_{I T}=x(p-c q)-a q^{2}-F, \quad \mathrm{E}[x]=E[k-\alpha p+(\beta+\tilde{\gamma}) q]$

The IT department's maximization problem and first order conditions are as follows:

$$
\begin{aligned}
& \operatorname{Max}_{p, q}\left\{E\left[S_{I T}\right]\right\}=\operatorname{Max}_{p, q}\left\{E\left[(k-\alpha p+(\beta+\tilde{\gamma}) q)(p-c q)-a q^{2}-F\right]\right\} \\
& k+\alpha(c-2 p+q)+\beta q=0 \\
& p(\alpha+\beta)-(k+c \beta+2 q(\alpha+\beta))=0
\end{aligned}
$$

Solving the first order conditions for optimal price and quality generates the following solution: 
$q^{* P C}=(k-c \alpha)(\beta-\alpha) /\left(4 a \alpha-(\beta-\alpha)^{2}\right)$

$p^{* P C}=(2 a(k+c \alpha)-(\beta-\alpha)(c \beta-k)) /\left(4 a \alpha-(\beta-\alpha)^{2}\right)$

Substituting (20) and (21) into the expressions for IT surplus, business unit surplus, and quantity from the demand function, and simplifying, we obtain the following:

$S_{I T}^{* P C}=\frac{a(k-c \alpha)^{2}}{4 a \alpha-(\beta-\alpha)^{2}}, S_{U}^{* P C}=\frac{2 a^{2} \alpha(k-c \alpha)^{2}}{\left(4 a \alpha-(\beta-\alpha)^{2}\right)^{2}}, x^{* P C}=\frac{2 a \alpha(k-c \alpha)}{4 a \alpha-(\beta-\alpha)^{2}}$

The firm benefit is the sum of IT profit and business unit surplus, $S_{I T}^{* P C}+S_{U}^{* P C}$ which can be simplified and expressed as follows:

$S_{f}^{* P C}=a(k-c \alpha)^{2}\left(6 a \alpha-(\beta-\alpha)^{2}\right) /\left(4 a \alpha-(\beta-\alpha)^{2}\right)^{2}$

Concavity Condition The Hessian matrix of the objective function (18) is given below:

$\left[\begin{array}{lr}-2(\alpha-\beta) & (\alpha-\beta) \\ (\alpha-\beta) & -2 \alpha\end{array}\right]$

The determinant is as follows: $4 a \alpha-(\alpha-\beta)^{2}$ and concavity requires that the determinant $4 a \alpha-(\alpha-\beta)^{2}>0$ because the first principal minor is negative. This in turn requires $a>(\alpha-\beta)^{2} / 4 \alpha$.

Positive Quality, Quantity and Price Note that concavity will ensure that the denominator for the expressions for optimal quantity and price is always positive and always negative for optimal quality. Setting (20) to be positive results in the requirement $\alpha<\beta$ and $\alpha<k / c$ or $k>c \alpha$ for non-negative quality. This will also ensure positive numerators for optimal quantity and price. Note that this becomes a necessary condition for price. Hence, we require $\alpha<\operatorname{Min}\{\beta, k / c\}$. A sufficient condition for positive price is $c \beta>k$ which is readily obtained by setting (21) to be positive.

This completes the proof.

\section{Proof of Proposition 3: Comparison of the profit center to the First Best benchmark}

(i) We compare firm benefit by taking the difference between the First Best benefit and profit center benefit from IT services: $\left(S_{f}^{* F B}-S_{f}^{* P C}\right)$, which results in the following expression:

$$
\frac{4 a^{3} \alpha^{2}(k-c \alpha)^{2}}{\left(2 a \alpha-(\beta-\alpha)^{2}\right)\left(4 a \alpha-(\beta-\alpha)^{2}\right)^{2}}
$$

Applying the feasibility conditions from lemmas 1, 2 and 3 , the difference is readily seen to be positive we have $\left(S_{f}^{* F B}-S_{f}^{* P C}\right)>0$.

(ii) We compare quality by taking the difference between the First Best quality and profit center quality of IT services: $\left(q^{* F B}-q^{* P C}\right)$. which results in the following expression:

$\frac{2 a \alpha(k-c \alpha)(\beta-\alpha)}{\left(2 a \alpha-(\beta-\alpha)^{2}\right)\left(4 a \alpha-(\beta-\alpha)^{2}\right)}$

Applying the feasibility conditions from lemmas 1, 2 and 3 , the difference is readily seen to be positive and we have $\left(q^{* F B}-q^{* P C}\right)>0$.

(iii) We compare price by taking the difference between the profit center price and First Best price of IT services: $\left(p^{* P C}-p^{* F B}\right)$, which results in the following expression:

$\frac{2 a(k-c \alpha)(2 a \alpha-(\beta-\alpha) \beta)}{\left(2 a \alpha-(\beta-\alpha)^{2}\right)\left(4 a \alpha-(\beta-\alpha)^{2}\right)}$

Applying the feasibility conditions from lemmas 1,2 and 3 , the difference is readily seen to be positive and we have $\left(p^{* P C}-p^{* F B}\right)>0$.

This completes the proof.

\section{Proof of Proposition 4: Comparison of quality of IT services between organizational structures}

The difference in optimal quality in the interior for the two governance structures is expressed as $\left(q^{* C C}-q^{* P C}\right)$. Solving this difference for the demand intercept $k$ we obtain the result:

$k>\frac{c \alpha\left(6 a \alpha(\beta+\alpha)-(\beta-\alpha)\left(3 \alpha \beta-(2 \alpha-1) \varepsilon^{2}\right)\right)}{(\beta-\alpha)\left(6 a \alpha-3 \alpha^{2}+(2 \alpha-1) \varepsilon^{2}\right)}$

(i) From the feasibility conditions for Lemmas 2 and 3, we have $\beta>\alpha$ and we also have $k>0$ because $k>c \alpha$. When $k>c \alpha$ we generate the condition $a>\frac{(\beta-\alpha)^{2}}{4 \alpha}>0$. The weaker condition is $k>0$ which requires $a>\frac{(\beta-\alpha)\left(3 \alpha \beta-(2 \alpha-1) \varepsilon^{2}\right)}{6 \alpha(\alpha+\beta)}$. Therefore, we have $a>\frac{(\beta-\alpha)^{2}}{4 \alpha}>\frac{\left.(\beta-\alpha)(3 \alpha \beta-(\alpha \alpha+\beta)-1) \varepsilon^{2}\right)}{6 \alpha(\alpha+\beta)}>0$. It is readily seen that this condition ensures that the numerator of (28) is positive. Which in turn requires the denominator 
to be positive and results in the necessary condition $a>\frac{3 \alpha^{2}-(2 \alpha-1) \varepsilon^{2}}{6 \alpha}$.

(ii) We also have $\frac{\partial q^{* C C}}{\partial k}=\frac{3(\beta-\alpha)}{6 a \alpha+6 \alpha \beta-3 \beta^{2}-(2 \alpha-1) \varepsilon^{2}}$ and $\frac{\partial q^{* P C}}{\partial k}=\frac{\beta-\alpha}{4 a \alpha-(\beta-\alpha)^{2}}$. The denominators are positive from Lemmas 2 and 3 and we have $\beta>\alpha$ from Lemma 2. To compare the change in optimal quality with respect to $k$ we check the difference $\left(\frac{\partial q^{* C C}}{\partial k}\right)-\left(\frac{\partial q^{* P C}}{\partial k}\right)$ which can be simplified and expressed as $\frac{(\beta-\alpha)\left(6 a \alpha-3 \alpha^{2}+\varepsilon^{2}\right)}{\left(4 a \alpha-(\alpha-\beta)^{2}\right)\left(6 a \alpha+6 \alpha \beta-3 \beta^{2}-\varepsilon^{2}\right)}$. Hence, for the difference $\left(\frac{\partial q^{* C C}}{\partial k}\right)-\left(\frac{\partial q^{* P C}}{\partial k}\right)$ to be positive we must have $\left(6 a \alpha-3 \alpha^{2}+\varepsilon^{2}\right)>0$, because all the other terms are positive, which implies that $a>\frac{3 \alpha^{2}-(2 \alpha-1) \varepsilon^{2}}{6 \alpha}$, which is the same condition as in part (i).

This completes the proof.

\section{Proof of proposition 5: Comparison of consumption of IT services}

The difference in quantity of IT services consumed under the two governance structures, from (22) and (14) is expressed as:

$\left(x^{* P C}-x^{* C C}\right)=\frac{2 a \alpha(k-c \alpha)}{4 a \alpha-(\beta-\alpha)^{2}}-\left(k+\frac{3 \beta(k(\beta-\alpha)-c \alpha \beta)}{6 \alpha(a+\beta)-3 \beta^{2}+(2 \alpha-1) \varepsilon^{2}}\right)$

Setting the difference $\left(x^{* P C}-x^{* C C}\right)=0$ has the form of a quadratic. Solving this quadratic for fixed cost of quality parameter $a$ we generate two solutions as follows:

$a=\frac{Y_{1} \mp \sqrt{Y_{2}}}{12 \alpha(k+c \alpha)}$

$Y_{1}=3 \alpha\left(k \alpha-2 \beta(k+c \alpha)+3 c \beta^{2}\right)-(k+c \alpha)(2 \alpha-1) \varepsilon^{2}$

$Y_{2}=\left(\begin{array}{l}9 \alpha\left(c^{2} \alpha \beta^{3}(5 \beta-4 \alpha)-2 c k \beta^{2}\left(2 \beta^{2}-\alpha^{2}\right)+k^{2}\left(\alpha^{3}-4 \alpha \beta^{2}+4 \beta^{3}\right)\right)+ \\ 6(k+c \alpha)\left(c \alpha \beta(3 \beta-2 \alpha)-k\left(2 \beta^{2}-2 \alpha \beta+\alpha^{2}\right)\right)(2 \alpha-1) \varepsilon^{2}+(k+c \alpha)^{2}(2 \alpha-1)^{2} \varepsilon^{4}\end{array}\right)$

The two roots are denoted as $a_{1}=\frac{Y_{1}+\sqrt{Y_{2}}}{12 \alpha(k+c \alpha)}$, and $a_{2}=\frac{Y_{1}-\sqrt{Y_{2}}}{12 \alpha(k+c \alpha)}$.

First, one of the two solutions from (30) is eliminated as it is shown to be infeasible. Note that the denominator of the two solutions is positive. The following steps lead to the elimination of $a_{2}$ as a solution.

Step 1: Compare terms between $Y_{1}$ and $Y_{2}$. Note that the last term in $Y_{1}$ is $(k+c \alpha)(2 \alpha-1) \varepsilon^{2}$ and the last term in $Y_{2}$ is $(k+c \alpha)^{2}(2 \alpha-1)^{2} \varepsilon^{4}$.

Step 2: Note that the fourth term in $Y_{1}$ is $9 c \alpha \beta^{2}$ and the first term in $Y_{2}$ is $\alpha^{2}\left(45 c^{2} \alpha^{2} \beta^{4}\right)$.

Step 3: For $a_{2}$ to have a positive value we must have $Y_{1}>\sqrt{Y_{2}}$. Steps 1 and 2 show that two terms in $Y_{1}$ are dominated by two terms in $\sqrt{Y_{2}}$. Therefore, it is necessary for the remaining term in $Y_{1}$ to be positive in order for $a_{2}$ to be positive. This requirement is checked in the next step.

Step 4: From Step 3, a necessary condition for $a_{2}$ to be positive is that $k \alpha-2 \beta(k+c \alpha)>0$ which yields the condition that $\beta<k \alpha / 2(k+c \alpha)$. However this contradicts the requirement in Lemma 2 for positive quality under the cost center $\beta<k \alpha /(k-c \alpha)$ because $k \alpha / 2(k-c \alpha)>k \alpha / 2(k+c \alpha)$. Therefore, $a_{2}>0$ is outside of the interior space and hence in the interior we have have $a_{2}<0$ which is infeasible.

Step 5: Because $Y_{1}>0$ is outside the interior space for the second root $a_{2}$, we must have $Y_{1} \leq 0$ which eliminates the second solution $a_{2}$ as it is negative, i.e. $a_{2}<0$.

Step 5: We now establish a verification of directionality, i.e. that when the fixed cost of quality $a<a_{1}$ the profit center generates greater consumption of IT services, and when $a>a_{1}$ the cost center generates greater consumption of IT services. Using the following values: $k=10$, $c=0.1, \varepsilon=2, \alpha=5, \beta=9$ we obtain the fixed cost of quality threshold $a_{1}=1.19032$.

Setting $a=\left(a_{1}-0.1\right)$ we have $x^{* P C}=25.6754$ and $x^{* C C}=18.8201$, and we have $x^{* P C}>x^{* C C}$.

Setting $a=\left(a_{1}+0.1\right)$ we have $x^{* P C}=15.0957$ and $x^{* C C}=18.4043$, and we have $x^{* P C}<x^{* C C}$.

Furthermore, note that $x^{* P C}=k-\alpha p^{* P C}+\beta q^{* P C}$ and $x^{* C C}=k+\beta q^{* P C}$. Hence, it can be readily seen that $x^{* P C}>x^{* C C}$ if and only if $\left(q^{* P C}-q^{* C C}\right)>(\alpha / \beta) p^{* P C}$.

This completes the proof.

\section{Proof of Proposition 6: The preferred IT organizational structure}

The expression for benefit to the firm from IT under the cost center organizational structure, for any realization of quality setting $q^{C C}$ under the cost center can be written as follows:

$S_{f}^{C C}=\frac{\left(k+\beta q^{C C}\right)^{2}}{2 \alpha}+\frac{q^{2} \varepsilon^{2}}{6 \alpha}-\left(c+q^{C C}\right)\left(k+\beta q^{C C}\right)-a\left(q^{C C}\right)^{2}-F$

Where $q^{C C}$ in (31) is any positive quality of IT service from the set of all possible quality values under the cost center $\left\{q^{C C}>0\right\}$. Next, from Lemma 3 we have the expression for the benefit to the firm under a profit center for any realization of quality and price:

$S_{f}^{P C}=\left(p^{P C}-(c+q)\right)\left(k-\alpha p^{P C}+\beta q^{P C}\right)-a\left(q^{P C}\right)^{2}-F$

(i) For the first part of Proposition 4, we consider the impact of fixed cost of quality on the choice of organizational structure. 
Step 1: Directionality

Clearly, the first partial derivatives with respect to the fixed cost of quality $a$ for (31) and (32) can be seen to be negative. Increasing the cost of quality will reduce IT profits, and reduce the benefit to the firm from IT. The difference in the first derivative with respect to fixed cost of quality parameter $a$ in (31) and (32) is as follows:

$\frac{\partial S_{f}^{C C}}{\partial a}-\left.\frac{\partial S_{f}^{P C}}{\partial a}\right|_{q^{P C}=q^{* P C}}=\left(\frac{(k-c \alpha)^{2}(\beta-\alpha)}{4 a \alpha-(\beta-\alpha)^{2}}\right)^{2}-\left(q^{C C}\right)^{2}$

The expression in (33) must also hold when $q^{C C}=q^{* C C}$. From (33) we can see that when the right hand side is positive, the benefit to the firm under the profit center is declining faster than the decline in benefit under the cost center, with increasing fixed cost of quality. Note that both $\partial S_{f}^{* C C} / \partial a$ and $\partial S_{f}^{* P C} / \partial a$ are negative. Therefore, when the right hand side of (33) is positive, the decline in profit center benefit is greater than the decline in cost center benefit when fixed cost of quality parameter $a$ increases. A positive value on the right hand side of (33) requires that $a<\frac{(\beta-\alpha)\left((k-c \alpha)^{2}+q^{* C C}(\beta-\alpha)\right)}{4 \alpha \cdot q^{* C C}}$. This is a positive threshold because Lemma 2 requires $\beta>\alpha$ in the interior and we have $q^{* C C}>0$. Hence, directionally, the fixed cost of quality $a$ needs to be sufficiently low for the profit center to be the preferred governance structure.
As in part (i), it is clear that the first partial derivatives with respect to the marginal cost $c$ for (31) and (32) are negative since increasing marginal cost will reduce profits, and reduce the benefit to the firm from IT. The difference in the first derivative with respect to marginal cost between (31) and (32) is as follows:

$\left.\frac{\partial S_{f}^{P C}}{\partial c}\right|_{q^{P C}=q^{* P C}}-\frac{\partial S_{f}^{C C}}{\partial c}=k+\frac{2 a \alpha(c \alpha-k)}{4 a \alpha-(\beta-\alpha)^{2}}+\beta\left(q^{C C}\right)$

The expression in (29) must also hold when $q^{C C}=q^{* C C}$. From (34) we can see that when the right hand side is positive, the benefit to the firm under the cost center is declining faster than the decline in benefit under the profit center, with increasing marginal cost $c$. Note that both $\partial S_{f}^{* P C} / \partial c$ and $\partial S_{f}^{* C C} / \partial c$ are negative. Therefore when the right hand side of (34) is positive, the decline in cost center benefits is more negative than the decline in profit center benefits when marginal cost $c$ is increasing. A positive value on the right hand side of (34) requires that $c>\frac{(\beta-\alpha)^{2}\left(k+\beta q^{* C C}\right)}{2 \alpha\left(k+c \alpha+2 \beta q^{* C C}\right)}$. This is a positive threshold because we require that $q^{* C C}>0$. Therefore, marginal cost $c$ needs to be sufficiently high for the profit center to be the preferred organizational structure for the IT department.

Step 2: Marginal cost threshold

Step 2: Fixed cost of quality threshold

Solving the identity $\left(S_{f}^{* P C}-S_{f}^{* C C}\right)=0$ with respect to $a$ the fixed cost of quality parameter generates only one real valued solution which is represented as follows in compact notation:

$a<\frac{\left(\begin{array}{c}-3 \alpha^{2}\left(p^{* P C}\right)^{2}+6 \alpha^{2} p^{* P C} q^{* P C}+6 k\left(q^{* P C}-q^{* C C}\right)(\beta-\alpha)-6 \alpha \beta\left(\left(q^{* P C}\right)^{2}-\left(q^{* C C}\right)^{2}\right) \\ +3 \beta^{2}\left(\left(q^{* P C}\right)^{2}-\beta^{2}\left(q^{* C C}\right)^{2}\right)+6 c \alpha\left(\alpha p^{* P C}+\beta q^{* C C}-\beta q^{* P C}\right)-(2 \alpha-1) \varepsilon^{2}\left(q^{* C C}\right)^{2}\end{array}\right)}{6 \alpha\left(\left(q^{* P C}\right)^{2}-\left(q^{* C C}\right)^{2}\right)}=a_{1}$

Where $p^{* P C}=(2 a(k+c \alpha)-(\beta-\alpha)(c \beta-k)) /$ $\left(4 a \alpha-(\beta-\alpha)^{2}\right), q^{* P C}=(k-c \alpha)(\beta-\alpha) /\left(4 a \alpha-(\beta-\alpha)^{2}\right)$, and $q^{* C C}=\frac{3(k(\beta-\alpha)-c \alpha \beta)}{6 \alpha(a+\beta)-3 \beta^{2}+(2 \alpha-1) \varepsilon^{2}}$

(ii) For the second part of Proposition 4, we consider the impact of marginal cost $c$ on the preferred organizational structure for the IT department.

Step 1: Directionality 
Solving the identity $\left(S_{f}^{* P C}-S_{f}^{* C C}\right)=0$ with respect to marginal quality $c$ generates two quadratic roots as follows: $c>\left(\frac{-Y_{1} \pm Y_{2} \sqrt{Y_{3}}}{Y_{4}}\right)=c_{1}$, where

Proof of Corollary 1: Demand uncertainty and preferred structure

Taking the derivative of the difference $\left(S_{f}^{* P C}-S_{f}^{* C C}\right)$ from

$Y_{1}=k\left(\begin{array}{l}144 a^{4} \alpha^{4}+6 a \alpha(\beta-\alpha)^{2}\left(3 \alpha \beta\left(3 \alpha^{2}-11 \alpha \beta+5 \beta^{2}\right)-2 \alpha(4 \beta-\alpha)(2 \alpha-1) \varepsilon^{2}-(2 \alpha-1)^{2} \varepsilon^{4}\right) \\ +4 a^{2} \alpha^{2}\left(9 \alpha\left(\alpha^{3}-12 \alpha^{2} \beta+20 \alpha \beta^{2}-8 \beta^{3}\right)+6 \alpha(4 \beta-3 \alpha)(2 \alpha-1) \varepsilon^{2}+(2 \alpha-1)^{2} \varepsilon^{4}\right) \\ +(\beta-\alpha)^{4}\left(9 \alpha(2 \alpha-\beta) \beta^{2}+6 \beta(2 \alpha-1) \varepsilon^{2}+(2 \alpha-1)^{2} \varepsilon^{4}\right) \\ -24 a^{3} \alpha^{3}\left(9 \alpha^{2}-18 \alpha \beta+3 \beta^{2}-2(2 \alpha-1) \varepsilon^{2}\right)\end{array}\right)$

$Y_{2}=k\left(4 \alpha a-(b-a)^{2}\right)\left(6 a(\alpha+b)-3 b^{2}+(2 a-1) e^{2}\right)$

$Y_{3}=\left(\begin{array}{l}72 a^{3} \alpha^{3}(2 a \alpha+(2 \alpha-\beta) \beta)+48 a^{3} \alpha^{3}(2 \alpha-1) \varepsilon^{2} \\ +\left(4 a^{2} \alpha^{2}-6 a \alpha(\beta-\alpha)^{2}+(\beta-\alpha)^{4}\right)(2 \alpha-1)^{2} \varepsilon^{4}\end{array}\right)$,

$Y_{4}=\alpha\left(\begin{array}{l}3(\beta-\alpha)^{4} \beta^{2}\left(6 \alpha \beta-3 \beta^{2}-2 \varepsilon^{2}+4 \alpha \varepsilon^{2}-432 a^{4} \alpha^{4}\right)+ \\ 12 a^{2} \alpha^{2}\left(3 \beta\left(4 \alpha^{3}-26 \alpha^{2} \beta+36 \alpha \beta^{2}-13 \beta^{3}\right)+2\left(\alpha^{2}-8 \alpha \beta+8 \beta^{2}\right)(2 \alpha-1) \varepsilon^{2}-(2 \alpha-1)^{2} \varepsilon^{4}\right) \\ +2 a \alpha(\beta-\alpha)^{2}\left(9 \beta^{2}\left(5 \alpha^{2}-14 \alpha \beta+6 \beta^{2}\right)+6(2 \alpha-1)(2 \alpha-5 \beta) \beta \varepsilon^{2}+(2 \alpha-1)^{2} \varepsilon^{4}\right) \\ +72 a^{3} \alpha^{3}\left(\alpha^{2}+11 \beta^{2}+2 \varepsilon^{2}-2 \alpha\left(7 \beta+2 \varepsilon^{2}\right)\right)\end{array}\right)$

Directionality has been established in step 1 above. From the requirements for an interior solution from Lemmas 2 and 3, we have $Y_{2}>0$ and therefore $Y_{2} \sqrt{Y_{3}}>0$. There are four possibilities for signs: $\left(Y_{1}>0, Y_{4}>0\right),\left(Y_{1}>0, Y_{4}<0\right),\left(Y_{1}<0, Y_{4}<0\right)$, $\left(Y_{1}<0, Y_{4}>0\right)$ Clearly, when $Y_{1}>0, Y_{4}>0$, the solution $c>\frac{-Y_{1}-Y_{2} \sqrt{Y_{3}}}{Y_{4}}$ is eliminated because the marginal cost threshold is negative. Similarly, when $Y_{1}<0, Y_{4}<0$, the solution $c>\frac{-Y_{1}+Y_{2} \sqrt{Y_{3}}}{Y_{4}}$ is also eliminated because the marginal cost threshold is negative. In the two other cases, only one solution from the pair will be valid because directionality has been established. Hence, only one solution from the pair can provide the required directionality in the feasible region. A numerical example is used to generate the feasible solution and is provided below:

Using the following parameter values: $\{k \rightarrow 10, \alpha \rightarrow 4, \beta$ $\rightarrow 10, \varepsilon \rightarrow 1, a \rightarrow 4\}$ it is readily seen that $Y_{1}<0, \quad Y_{2} \sqrt{Y_{3}}>0, \quad Y_{4}>0$. Only one solution $\frac{-Y_{1}+Y_{2} \sqrt{Y_{3}}}{Y_{4}}$ generates positive quality as required for and interior solution with these parameter values. We compute the marginal cost threshold $c_{1}=0.700797$ as the marginal cost above which the profit center is predicted to generate greater firm benefits. Directionality is verified using values for marginal cost above and below the threshold $c=c_{1}=0.700797 \pm 0.1$ to check for the difference in firm benefit $\left(S_{f}^{* P C}-S_{f}^{* C C}\right)$ and we obtain $\left.\left(S_{f}^{* P C}-S_{f}^{* C C}\right)\right|_{c=c_{1}=0.700797+0.1}=1.71766>0$ when the marginal cost is above $c_{1}$ which confirms that the profit center provides greater firm benefit. We also obtain $\left.\left(S_{f}^{* P C}-S_{f}^{* C C}\right)\right|_{c=c_{1}=0.700797-0.1}=-1.9442<0$ when the marginal cost is below $c_{1}$ which confirms that the cost center provides greater firm benefit. Hence, we have $c_{1}=\frac{-Y_{1}+Y_{2} \sqrt{Y_{3}}}{Y_{4}}$.

This completes the proof.
Lemmas 2 and 3, we obtain the following:

$\left(\frac{\partial S_{f}^{* P C}}{\partial \varepsilon}-\frac{\partial S_{f}^{* C C}}{\partial \varepsilon}\right)=\frac{6(2 \alpha-1)^{2}(c \alpha \beta-k(\beta-\alpha))^{2} \varepsilon^{3}}{\alpha\left(6 \alpha(a+\beta)-6 \beta^{2}+(2 \alpha-1) \varepsilon^{2}\right)^{3}}>0$

The requirements for an interior solution from Lemmas 1 and 2 show that the difference in (35) is positive.

This completes the proof.

\section{Proof of Proposition 7: Preferred IT organizational structure and variety of IT services}

Proposition 4 specifies the marginal cost $c_{1}$ at which the firm is indifferent between the profit center and the cost center structure. All exogenous parameters are identical for all services except for the fixed cost $F_{i}, i=1,2, \ldots, \psi$ which does not play a role in the optimization undertaken by the firm or by the IT department. Hence, the indifference point $c_{1}$ reported in Lemma 3 is identical for all services. Furthermore, the IT services are ordered in their benefit to the firm and IT profit.

First, we show that when $c<c_{1}$ the cost center is always the preferred structure and the profit center will never offer greater number of services. Proposition 5 reports that when $c<c_{1}$ the cost center is the preferred organizational structure for each service, because $S_{f i}^{C C}>S_{n i}^{P C}>S_{I T i}, i=1,2, \ldots, \psi$. Therefore, we have $\sum_{i=1}^{n} S_{f i}^{C C}>\sum_{i=1}^{n^{f}} S_{f i}^{P C}$ and $\sum_{i=1}^{m} S_{f i}^{C C}>\sum_{i=1}^{m} S_{f i}^{P C}$. We also know that the number of services offered by the cost center is $n$ and therefore we know that $S_{f n+1}^{C C}<0$. However, we also have $S_{f i}^{C C}>S_{f i}^{P C}>S_{I T i}, i=1,2, \ldots, \psi$ which implies that $0>S_{f n+1}^{C C}>S_{I T n+1}$. Therefore, the greatest possible value for the number of services offered by the profit center is $n$ because $n<m$ will result in $S_{I T n+1}>0>S_{f n+1}^{C C}$ which is a contradiction. Therefore, we have the result $n \geq m$. 
Second, we derive the marginal cost threshold $c_{v}$ such that when $c=c_{v}$ the cost center benefit to the firm is zero for service $m+1$ such that $S_{f m+1}^{C C}=0$, and when $c>c_{v}$ the cost center benefit to the firm for service $m+1$ is negative such that $S_{f i m+1}^{C C}<0$. The threshold $c_{v}$ is obtained by solving for marginal cost when $S_{f m+1}^{* C C}=0$, where $S_{f}^{* C C}$ is as reported in Lemma 1 as follows, for service $m+1$ :

$S_{f}^{* C C}==\frac{\left(\begin{array}{l}36 a^{2} c k \alpha^{2}+9 a\left(2 c k \alpha(3 \alpha-2 \beta) \beta-c^{2} \alpha^{2} \beta^{2}+k^{2}\left(\beta^{2}-\alpha^{2}\right)\right)+ \\ 12 a c k \alpha(2 \alpha-1) \varepsilon^{2}+\left(3(\beta-\alpha)(k-c \beta)+c(2 \alpha-1) \varepsilon^{2}\right) \\ \left(3 \alpha \beta(k-c \beta)+k(2 \alpha-1) \varepsilon^{2}\right)\end{array}\right)}{2 \alpha\left(6 \alpha(a+\beta)-3 \beta^{2}+(2 \alpha-1) \varepsilon^{2}\right)^{2}}-F_{m+1}$
$S_{I T i}+S_{U i}^{P C}>S_{f i}^{C C}, i=1,2, \ldots, \psi$ which in turn implies $S_{f i}^{P C}>S_{f i}^{C C}, i=1,2, \ldots, \psi$ and the cost center will never be the preferred structure. Hence, when the cost center is the preferred structure, it can never be that $S_{I T i}>S_{f i}^{C C}, i=1,2, \ldots, \psi$, and it must be that $S_{I T i}<S_{f i}^{C C}, i=1,2, \ldots, \psi$. We also know from that the cost center will offer $m$ services and we have $\sum_{i=1}^{n} S_{f i}^{C C}>\sum_{i=1}^{m} S_{f i}^{P C}$.
The solution to (36) generates two roots for marginal cost and one root is readily eliminated by substituting the two roots for cost center quality $q^{* C C}$ and only the following solution generates positive cost center quality. The other root is outside the feasible region and we have.. and we have $S_{f n+1}^{P C}<0$. If $m>n$ then we will have $S_{I T n+1}>0$ which is a contradiction because $S_{I T n+1}<S_{f n+1}^{C C}$ Therefore, it must be that $n \geq m$.

This completes the proof.

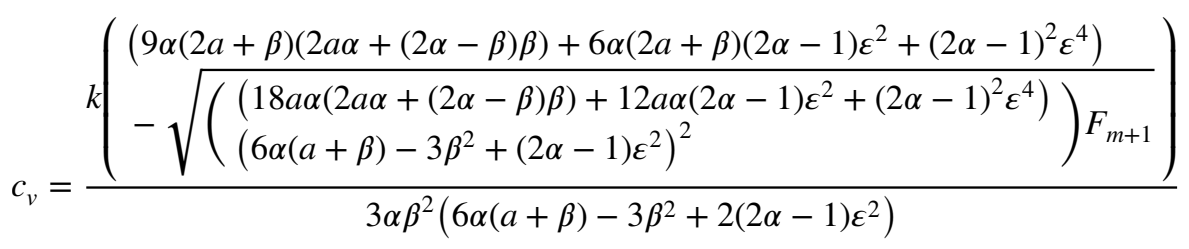

Third, the derivative of cost center firm benefit with respect to marginal cost $c$ is computed as follows:

$\frac{\partial S_{f}^{* C C}}{\partial c}=-\left(\begin{array}{l}9 \alpha(2 a \alpha+(2 \alpha-\beta) \beta)(2 a k+\beta(k-c \beta))+ \\ \frac{6 \alpha(2 a k+\beta(k-c \beta))(2 \alpha-1) \varepsilon^{2}+k(2 \alpha-1)^{2} \varepsilon^{4}}{\left(6 a \alpha+3 \beta(2 \alpha-\beta)+(2 \alpha-1) \varepsilon^{2}\right)^{2}}\end{array}\right)$

Imposing the concavity condition $\alpha>\frac{\beta^{2}}{2(\alpha+\beta)}$ from the proof of Lemma 3 ensures that (38) is negative.

Fourth, consider the case when $c<c_{v}$. When the profit center is the preferred structure we know that $\sum_{i=1}^{m} S_{f i}^{P C}>\sum_{i=1}^{m} S_{f i}^{C C}$ and we also have $S_{I T m+1}<0$. However from (37) we know that when $c<c_{v}$ the cost center firm benefit from service $m+1$ is positive and we have $S_{f m+1}^{C C}>0$. This implies that the cost center will offer IT service $m+1$. We also know that the profit center will offer only offer $m$ services. Therefore, even when the profit center is preferred, the cost center will offer more services when $c \in\left(c_{1}, c_{v}\right)$.

Now consider the second part of the proposition when the cost center is the preferred structure and $c<c_{v}$ When $c<c_{v}$ we have $S_{I T i}<S_{f i}^{C C}, i=1,2, \ldots, \psi$ because the converse $S_{I T i}>S_{f i}^{C C}, i=1,2, \ldots, \psi \quad$ implies that 


\section{Proof of Proposition 8: Uncertainty and variety under the profit center}

From the result in Proposition 7, we take the derivative $\partial c_{\nu} / \partial \varepsilon$ and we have:

$\frac{\partial c_{\nu}}{\partial \varepsilon}=\left(\int^{\left(4 k(2 \alpha-1)^{2} \varepsilon^{3}\left(6 \alpha(a+\beta)-3 \beta^{2}+(2 \alpha-1) \varepsilon^{2}\right)\right)}\right.$

$\left(3 \alpha \beta^{2}\left(6 \alpha(a+\beta)-3 \beta^{2}+2(2 \alpha-1) \varepsilon^{2}\right)^{2}\right)$

The fixed cost $F_{m+1}$ is notionally set to unity for tractability and ease of exposition. Imposing the concavity condition $a>\frac{3 \beta(\beta-2 \alpha)-(2 \alpha-1) \varepsilon^{2}}{6 \alpha}$ from Lemma 2 and testing for sign with the following values $a=\frac{6 \beta(\beta-2 \alpha)-(2 \alpha-1) \varepsilon^{2}}{6 \alpha}+10.8$ and $\{k=10, \alpha=6, \beta=7, \varepsilon=5\}$, the derivative $\frac{\partial c_{v}}{\partial \varepsilon}=-0.0291433<0$. Furthermore, imposing the feasibility conditions from Lemmas 2 and 3 ensures that $\frac{\partial c_{v}}{\partial \varepsilon}<0$.

This completes the proof.

Open Access This article is licensed under a Creative Commons Attribution 4.0 International License, which permits use, sharing, adaptation, distribution and reproduction in any medium or format, as long as you give appropriate credit to the original author(s) and the source, provide a link to the Creative Commons licence, and indicate if changes were made. The images or other third party material in this article are included in the article's Creative Commons licence, unless indicated otherwise in a credit line to the material. If material is not included in the article's Creative Commons licence and your intended use is not permitted by statutory regulation or exceeds the permitted use, you will need to obtain permission directly from the copyright holder. To view a copy of this licence, visit http://creativecommons.org/licenses/by/4.0/.

\section{References}

Aasi, PI. (2018). Information technology governance: The role of organizational culture and structure. PhD dissertation, Department of Computer and Systems Sciences, Stockholm University.

Acemoglu, D., Aghion, P., Lelarge, C., Van Reenen, J., \& Zilibotti, F. (2007). Technology, information, and the decentralization of the firm. The Quarterly Journal of Economics, 122(4), 1759-1799.

Ali, S., \& Green, P. (2012). Effective information technology (IT) governance mechanisms: An IT outsourcing perspective. Information Systems Frontiers, 14(2), 179-193.

Allen, B. (1987). Make information services pay its way. Harvard Business Review, 65(1), 57-63.

Alperovich, G., \& Weksler, I. (1996). A class of utility functions yielding linear demand functions. The American Economist, 40(1), $20-23$.

Banker, R. D., Khosla, I., \& Sinha, K. K. (1998). Quality and competition. Management Science, 44(9), 1179-1192.

Bergeron, F. (1986). The success of DP charge-back systems from a user's perception. Information \& Management, 10(4), 187-195.

Box, G. E. (1976). Science and statistics. Journal of the American Statistical Association, 71(356), 791-799.
Choudhary, V., \& Vithayathil, J. (2013). The impact of cloud computing: Should the IT department be organized as a cost center or a profit center? Journal of Management Information Systems, 30(2), 67-100.

Colecchia, A., \& Schreyer, P. (2002). ICT investment and economic growth in the 1990s: Is the United States a unique case?: A comparative study of nine OECD countries. Review of Economic Dynamics, 5(2), 408-442.

Cumbie, B. A., \& Sankar, C. S. (2012). Choice of governance mechanisms to promote information sharing via boundary objects in the disaster recovery process. Information Systems Frontiers, 14(5), 1079-1094.

Cumming, D., Johan, S., \& Schweizer, D. (2017). Information systems, agency problems, and fraud. Information Systems Frontiers, 19(3), 421-424.

Dawson, G. S., Denford, J. S., Williams, C. K., Preston, D., \& Desouza, K. C. (2016). An examination of effective IT governance in the public sector using the legal view of agency theory. Journal of Management Information Systems, 33(4), 1180-1208.

Delone, W. H., \& McLean, E. R. (2003). The DeLone and McLean model of information systems success: A ten-year update. Journal of Management Information Systems, 19(4), 9-30.

Dewan, S. (1996). Pricing computer services under alternative control structures: Tradeoffs and trends. Information Systems Research, 7(3), 301-307.

Dewan, S., \& Mendelson, H. (1990). User delay costs and internal pricing for a service facility. Management Science, 36(12), $1502-1517$.

Dixit, A. (1979). A model of duopoly suggesting a theory of entry barriers. The Bell Journal of Economics, 10(1), 20-32.

Drury, D. H. (1997). Chargeback Systems in Client/server environments. Information \& Management, 32(4), 177-186.

S. Florentine. (2017). 10 IT skills that employers need in 2017. CIO. com, http://www.cio.com/article/3164125/hiring/10-it-skills-thatemployers-need-in-2017.html\#slide1

Fredrik, L., Rusu, L, Aasi, P. (2015). Organizational Structure in IT Governance: A Case Study of an IT Governance Implementation Project." 21 st Americas Conference on Information Systems (AMCIS 2015), Puerto Rico, august 13-15, 2015. Association for Information Systems.

Gal-Or, E. (1985). Information sharing in oligopoly. Econometrica, 53(2), 329-343.

Gal-Or, E., \& Ghose, A. (2005). The economic incentives for sharing security information. Information Systems Research, 16(2), 186-208.

Gordon, S. (1994). Benchmarking the information systems function. Center for Information Management Studies (CIMS), CIMS working paper series 94-08, Babson College.

Gurbaxani, V. C., \& Kemerer, C. F. (1988). An agency theory view of the Management of end-User Computing. Sloan School of Management.

Gurbaxani, V., Kemerer, C.F. (1989). An agent-theoretic perspective on the Management of Information Systems. Proceedings of the Twenty-Second Annual Hawaii International Conference on System Sciences, IEEE.

Hann, J., \& Weber, R. (1996). Information systems planning: A model and empirical tests. Management Science, 42(7), 1043-1064.

Jensen, M. C., Meckling, W. H. (1998). Divisional performance measurement. Foundations of Organizational Strategy, Harvard University Press, Chapter 12.

Joe-Wong, C., \& Sen, S. (2018). Harnessing the power of the cloud: Revenue, fairness, and cloud neutrality. Journal of Management Information Systems, 35(3), 813-836.

Luo, J., Wu, Z., Huang, Z., Wang, L. (2016). Relational IT governance, its antecedents and outcomes: A study on Chinese firms. Thirty 
seventh international conference on information systems (ICIS), Dublin, 2016.

Magal, S. R. (1991). A model for evaluating information center success. Journal of Management Information Systems, 8(1), 91-106.

Mendelson, H. (1985). Pricing computer services: Queueing effects. Communications of the ACM, 28(3), 312-321.

Oi, W. Y. (1962). Labor as a quasi-fixed factor. Journal of Political Economy, 70(6), 538-555.

Overby, S. (2004). USAA: I.T. incorporated. CIO.com, http://www.cio. com/article/32260/USAA_I.T._Incorporated.

Peterson, R. (2004). Crafting information technology governance. Information Systems Management, 21(4), 7-22.

Pick, R. A., \& Whinston, A. B. (1989). A computer charging mechanism for revealing user preferences within a large organization. Journal of Management Information Systems, 6(1), 87-100.

Porter, M. E., \& Heppelmann, J. E. (2015). How smart, connected products are transforming companies. Harvard Business Review, 93(10), 96-114.

Ross, J. W., Vitale, M. R., \& Beath, C. M. (1999). The untapped potential of IT chargeback. MIS Quarterly, 23(2), 215-237.

Sharma, N., \& Gupta, S. (2019). An investigation of IT-intervention adoption in public distribution system: A stakeholder and agency theory perspective. Information Development, 35(2), 203-219.

Singh, N., \& Vives, X. (1984). Price and quantity competition in a differentiated duopoly. The Rand Journal of Economics, 15(4), $546-554$.

Stablein, T. P. (2018). Improving strategic IT investment decisions by reducing information asymmetry. Graduate Theses and Dissertations. https://scholarcommons.usf.edu/etd/7577/

Stinchcombe, A. L. (1990). Information and organizations (Vol. 19). University of California Press.

Techworld. (2004). The rapid rise of chargeback. Techworld, http:// features.techworld.com/applications/803/the-rapid-rise-of-charg eback/.

Tirole, J. (1988). The theory of industrial organization. MIT Press.
Tonelli, A. O., de Souza Bermejo, P. H., Dos Santos, P. A., Zuppo, L., \& Zambalde, A. L. (2017). IT governance in the public sector: A conceptual model. Information Systems Frontiers, 19(3), 593-610.

Varian, H. R. (1992). Microeconomic analysis (Vol. 2). Norton.

Vejseli, S., Rossmann, A. (2017). The Impact of IT Governance on Firm Performance A Literature Review. In Pacific Asia Conference on Information Systems (PACIS 2017), p. 41.

Versteeg, G., \& Bouwman, H. (2006). Business architecture: A new paradigm to relate business strategy to ICT. Information Systems Frontiers, 8(2), 91-102.

Vives, X. (1984). Duopoly information equilibrium: Cournot and Bertrand. Journal of Economic Theory, 34(1), 71-94.

Wang, E. T. G., \& Barron, T. (1995). Controlling information system departments in the presence of cost information asymmetry. Information Systems Research, 6(1), 24-50.

Weinzimer, P. (2015). How to Measure and Improve the Business Value of IT Service. http://www.ittoday.info/ITPerformanceImprove ment/Articles/2015-02Weinzimer.html

Wiedenhöft, G. C., Luciano, E. M., \& Pereira, G. V. (2020). Information technology governance institutionalization and the behavior of individuals in the context of public organizations. Information Systems Frontiers, 22(6), 1487-1504.

Wu, S. P. J., Straub, D. W., \& Liang, T. P. (2015). How information technology governance mechanisms and strategic alignment influence organizational performance: Insights from a matched survey of business and IT managers. Management Information Systems Quarterly, 39(2), 497-518.

Yadav, S. B. (1985). Classifying an organization to identify its information requirements: A comprehensive framework. Journal of Management Information Systems, 2(1), 39-60.

Publisher's Note Springer Nature remains neutral with regard to jurisdictional claims in published maps and institutional affiliations. 